\title{
Point-of-care ultrasound in primary care: a systematic review of generalist performed point-of-care ultrasound in unselected populations
}

\author{
Bjarte Sorensen ${ }^{1^{*}}$ (10 and Steinar Hunskaar ${ }^{2,3}$
}

\begin{abstract}
Background: Both the interest and actual extent of use of point-of-care ultrasound, PoCUS, among general practitioners or family physicians are increasing and training is also increasingly implemented in residency programs. However, the amount of research within the field is still rather limited compared to what is seen within other specialties in which it has become more established, such as in the specialty of emergency medicine. An assumption is made that what is relevant for emergency medicine physicians and their populations is also relevant to the general practitioner, as both groups are generalists working in unselected populations. This systematic review aims to examine the extent of use and to identify clinical studies on the use of PoCUS by either general practitioners or emergency physicians on indications that are relevant for the former, both in their daily practice and in out-of-hours services.
\end{abstract}

Methods: Systematic searches were done in PubMed/MEDLINE using terms related to general practice, emergency medicine, and ultrasound.

Results: On the extent of use, we identified 19 articles, as well as 26 meta-analyses and 168 primary studies on the clinical use of PoCUS. We found variable, but generally low, use among general practitioners, while it seems to be thoroughly established in emergency medicine in North America, and increasingly also in the rest of the world. In terms of clinical studies, most were on diagnostic accuracy, and most organ systems were studied; the heart, lungs/ thorax, vessels, abdominal and pelvic organs, obstetric ultrasound, the eye, soft tissue, and the musculoskeletal system. The studies found in general either high sensitivity or high specificity for the particular test studied, and in some cases high total accuracy and superiority to other established diagnostic imaging modalities. PoCUS also showed faster time to diagnosis and change in management in some studies.

Conclusion: Our review shows that generalists can, given a certain level of pre-test probability, safely use PoCUS in a wide range of clinical settings to aid diagnosis and better the care of their patients.

Keywords: General practice, Family medicine, Emergency medicine, Point-of-care ultrasound, Ultrasound

\section{Background}

Point-of-care ultrasound, PoCUS, can be defined as the use of an image-producing ultrasound device for diagnostic and procedural guidance, by the clinician himself, at the point of care, in real time allowing for direct

\footnotetext{
${ }^{*}$ Correspondence: bjarte.sorensen@gmail.com

${ }^{1}$ Hjelmeland General Practice Surgery, Prestagarden 13, 4130 Hjelmeland, Norway

Full list of author information is available at the end of the article
}

correlation with signs and symptoms [1]. It is integrated in the clinical work, and may increase accuracy of diagnoses or aid procedures, as well as reduce time spent to diagnoses and decreased overall costs [2].

General practitioners (GPs), or family physicians, work in a range of settings and levels of urgencies, from daytime run clinics, through out-of-hours $(\mathrm{OOH})$ services such as primary care urgent care centres, to the provision of undifferentiated emergency medicine in rural and 
remote regions. Globally, there are many different organisational models for $\mathrm{OOH}$ services, often running in parallel, including GP rota groups, cooperatives, primary care centres, as well as in-hospital emergency departments [3].

General practitioners are trained to manage both chronic conditions as well as acute emergencies, often within the same session, seeing women and men, young and old. In many countries, such as Australia [4] and Canada [5], general practitioners in rural and remote areas are expected to handle all emergencies and are often the only physicians available for initial diagnosis, management, and stabilisation within several hours of travel by road, water, or air. In countries such as Norway [6] and New Zealand [7], GPs are organised as part of the emergency response chain acting as a first responder and a team member to the ambulance services. Skills such as obtaining peripheral venous access and diagnosing life-threatening medical and traumatological conditions are expected $[8,9]$.

There are, therefore, many settings where the GP could potentially benefit from her own use of PoCUS. Both the interest and actual extent of use among GPs are increasing and PoCUS training is also increasingly implemented in residency programs [10]. However, the amount of research on PoCUS performed by GPs is still rather limited compared to other specialties in which it has become more established, such as in the specialty of emergency medicine $[11,12]$.

A recently published systematic review of PoCUS in general practice, identifying articles where the operators were GPs, concluded that it has the potential to be an important tool for the GP and possibly reduce health costs, but emphasises the need for further research [12]. Meanwhile, we think that it may be useful to also review studies where the setting is similar and the PoCUS operators also are, like GPs, physicians with a generalist training and perspective. We made the assumption that findings from studies where the operator is an emergency physician (EP) working in an unselected emergency department population also will be relevant for GPs.

The aim of this systematic review is thus twofold: first, to examine the extent of use among both GPs and EPs; second, to identify primary clinical research articles or meta-analyses on PoCUS for indications relevant for GPs in which the population is unselected (open GP practice or emergency departments) and the operators are either GPs or EPs.

\section{Methods}

Systematic searches were performed in the PubMed databases. Indexed MEDLINE-articles were identified by medical subject headings' (MeSH) keywords describing ultrasound, general practice, and emergency medicine (Table 1). Non-indexed PubMed articles were identified by corresponding keywords (Appendix 2 shows the exact search algorithm). The reference lists of included articles were also reviewed.

Only studies involving the clinical use of two-dimensional image-producing ultrasound at the point of care were included. Studies on hospitalised inpatients were excluded, as well as studies where the operator was a non-generalist, non-physician, or prehospital emergency medical service personnel. Case studies or case series were excluded, as were the use of ultrasound on hyperacute indications or for procedures less likely to be of relevance to most general practitioners (Appendix 1). Meta-analyses where the majority of the included articles fit our inclusion criteria were included, and the individual studies analyzed by these meta-analyses were excluded from our review to avoid double treatment. Articles published after the latest meta-analyses were included, as were articles outside the scope of the metaanalyses identified. Articles in other languages than English, German, Spanish, or any of the Scandinavian languages were excluded. The search was last performed on 1 June 2019.

\section{Results}

We identified 15,745 articles which were screened for eligibility, and after screening, 1413 full text articles we were left with 213 articles for inclusion, as shown in Fig. 1. Out of these, 19 were articles about the extent of use, while 26 were meta-analyses, and 168 primary research studies on PoCUS.

Table 1 Search algorithms

\begin{tabular}{|c|c|c|c|}
\hline MeSH terms & $\begin{array}{l}\text { Ultrasonography (included echocar- } \\
\text { diography) }\end{array}$ & $\begin{array}{l}\text { Primary health care } \\
\text { General practice (included family } \\
\text { practice) } \\
\text { General practitioners } \\
\text { Physicians, primary care } \\
\text { Physicians, family }\end{array}$ & $\begin{array}{l}\text { Emergency medical services } \\
\quad \text { (included emergency } \\
\text { service, hospital) } \\
\text { Emergency medicine } \\
\text { Emergency treatment } \\
\text { Emergencies }\end{array}$ \\
\hline $\begin{array}{l}\text { Additional keywords used for search in } \\
\text { non-indexed articles }\end{array}$ & $\begin{array}{l}\text { Ultrasound } \\
\text { POCUS } \\
\text { Echocardiography }\end{array}$ & $\begin{array}{l}\text { General practitioner } \\
\text { Primary care physician } \\
\text { Family physician }\end{array}$ & $\begin{array}{l}\text { Emergency physician } \\
\text { Prehospital medicine }\end{array}$ \\
\hline
\end{tabular}




\section{The extent of use}

There is great variation in the extent of use of PoCUS among GPs in Europe. In Norway, 23\% of emergency primary care centres had access to their own ultrasound machines in 2015. However, only 1 of 15 of the GPs working there used ultrasound ever and only $0.3 \%$ of billings included an ultrasound item [13]. Ultrasound was in 2014 commonly used in Germany (about 45\%) and Greenland (about two-thirds), while it was less commonly used in Sweden, Denmark, Austria, and Catalonia $(<1 \%)$ [14]. GPs, and EPs, working in emergency departments in rural Canada had good access to ultrasound equipment already in 2013 and increasingly until today (60-95\%), while between 44 and $76 \%$ reported, they used ultrasound, a third of these on every shift [15-17].

Among EPs, ultrasound was used in 5\% of the consultations in emergency departments in France in 2014 [18]. French emergency departments (EDs) have seen an increase in the availability of ultrasound equipment from 52 to 71\% between 2011 and 2016 [19]. EPs had access to ultrasound equipment in $89 \%$ of Danish emergency departments in 2013 [20]. In China, 54\% of EPs reported having access to equipment in 2016, and 43\% of respondents reported using PoCUS in their clinical work [21]. In South Korea, it was available in 2014 in all surveyed EDs and $82.7 \%$ of respondents used PoCUS daily on adult patients, but only $23.6 \%$ performed

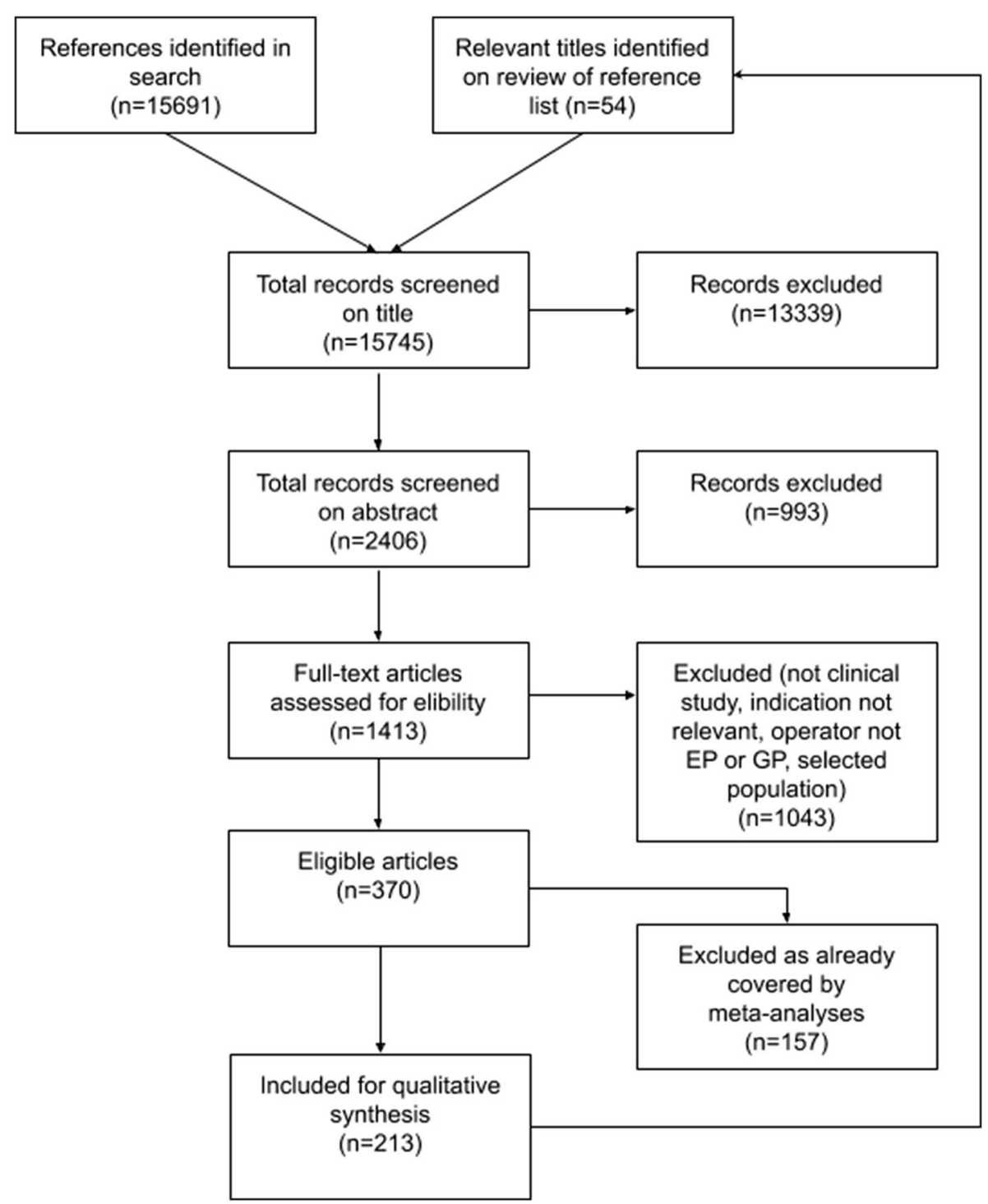

Fig. 1 Study selection flow diagram 
paediatric PoCUS daily [22]. In Colombia, 57\% of all emergency medicine residents responded that they lacked equipment, while $52 \%$ responded that they had used ultrasound during their training [23]. The use of PoCUS is integrated in the emergency physician training in the USA [24], and from 2004 to 2015, the access to equipment in emergency departments has risen from $19 \%$ to between 66 and $96 \%$, and the lack of physician training is now seen as the major barrier rather than the lack of available technology [25-30].

\section{Relevant indications}

We found 26 meta-analyses and 168 primary studies on PoCUS used by generalists on a wide range of indications that we deemed relevant for the general practitioner, and they have been sorted according to the relevant organ systems: heart, lungs, vessels, abdomen, obstetric ultrasound, the eye; soft tissue, and musculoskeletal system.

The most studied parameter was diagnostic accuracy, and Tables 2, 3, 4, 5, 6, 7 and 8 show the test characteristics of a multitude of examinations. The sensitivities and specificities are displayed, and 95\% confidence intervals are included where available. Positive and negative likelihood ratios $(\mathrm{LR}+/ \mathrm{LR}-)$ have been listed rather than positive and negative predictive values, as the former are prevalence independent, while the latter is only valid for the given prevalence in the studied population. Where either of the tabulated parameters was not available, we calculated these from the given data and indicated as such in the tables. Where available, the amount of time spent on specific didactic teaching is listed.

To the extent any other parameters than diagnostic accuracy were studied, this is presented narratively in the below text.

\section{Heart}

Studies on indications relating to the heart are summarized in Table 2. Even though a GP in a Norwegian pilot study from 1985 concluded that "echocardiography will not have any diagnostic significance in general practice in the foreseeable future" [31], a similar UK study was more positive in 1998 where one found GP performed evaluation of left-ventricular function frequently altered management [32].

Three studies from the last few years evaluated GPs' use of echocardiography compared to cardiologist as the reference, all of which found that, after 4-28 h of instruction, the GP could assess left-ventricular form and function with an accuracy high enough to impact management [33-35]. GPs have been found to reliably measure the mitral annular plane systolic excursion (MAPSE) through the use of pocket ultrasound after an $8 \mathrm{~h}$ teaching program with a sensitivity of $83 \%$ and a specificity of $78 \%$ [33]. A Spanish study found high accuracy for detecting left-ventricular hypertrophy (LVH) with GP operated pocket ultrasound in hypertensive patients in general practice, with a LR+ of 56 and a LR- of 0.1 [34]. They also found clinically useful test accuracy for other abnormalities. Another Spanish study found that GPs using pocket echocardiography on several indications had a very high specificity (93-100\%) for a range of diagnoses, including LVH and valvular pathologies, but a rather low sensitivity (41-72\%) [35].

Nine studies showed that EPs of varying experience could estimate left-ventricular ejection fraction (LVEF) and showed an overall agreement with cardiologists of between 84 and 93\%, both on visual estimation and calculated values using, e.g., E-point septal separation [36-44]. Another study showed good agreement between EPs and cardiac sonographers on obtaining windows for left-ventricular outflow tract for velocity time integral studies [45], and it has been shown that EPs were able to obtain those windows for more than half of their ED patients [46]. Three studies identified high sensitivities and moderate-to-very good agreement with cardiologists for detection of diastolic dysfunction [47-49], while an Italian study found a high correlation between EP findings of restrictive mitral pattern and the presence of leftventricular heart failure, with an LR+ of 8.27 [50]. EPs have also been shown to have good inter-rater agreement for the assessment of overall diastolic function [51].

Emergency physicians ability to detect wall motion abnormalities showed very good agreement with cardiologists in two studies [43, 52], while a 2018 US study sought to find whether EPs could use speckle tracking software to identify wall motion abnormalities and found that the sensitivity was low at $29 \%$, but specificity high at $88 \%$ [53].

The ability to detect pericardial fluid by EPs was studied in four studies which all found sensitivities from 60 to $96 \%$ and specificities from 96 to $100 \%$ despite short training periods. False-negative findings were more likely for smaller effusions [39, 42, 43, 54].

\section{Lungs}

Findings from studies on lung ultrasound are detailed in Table 3. Lung ultrasound (LUS) can be used to detect diffuse interstitial syndrome (bilateral B lines), which, in the setting of suspected acute decompensated heart failure (ADHF), likely signifies pulmonary oedema. We identified five meta-analyses on this utility of LUS in the emergency department, all concluding that both the sensitivity and specificity are very high [55-59], and indeed the one test with the best test characteristics compared to all 


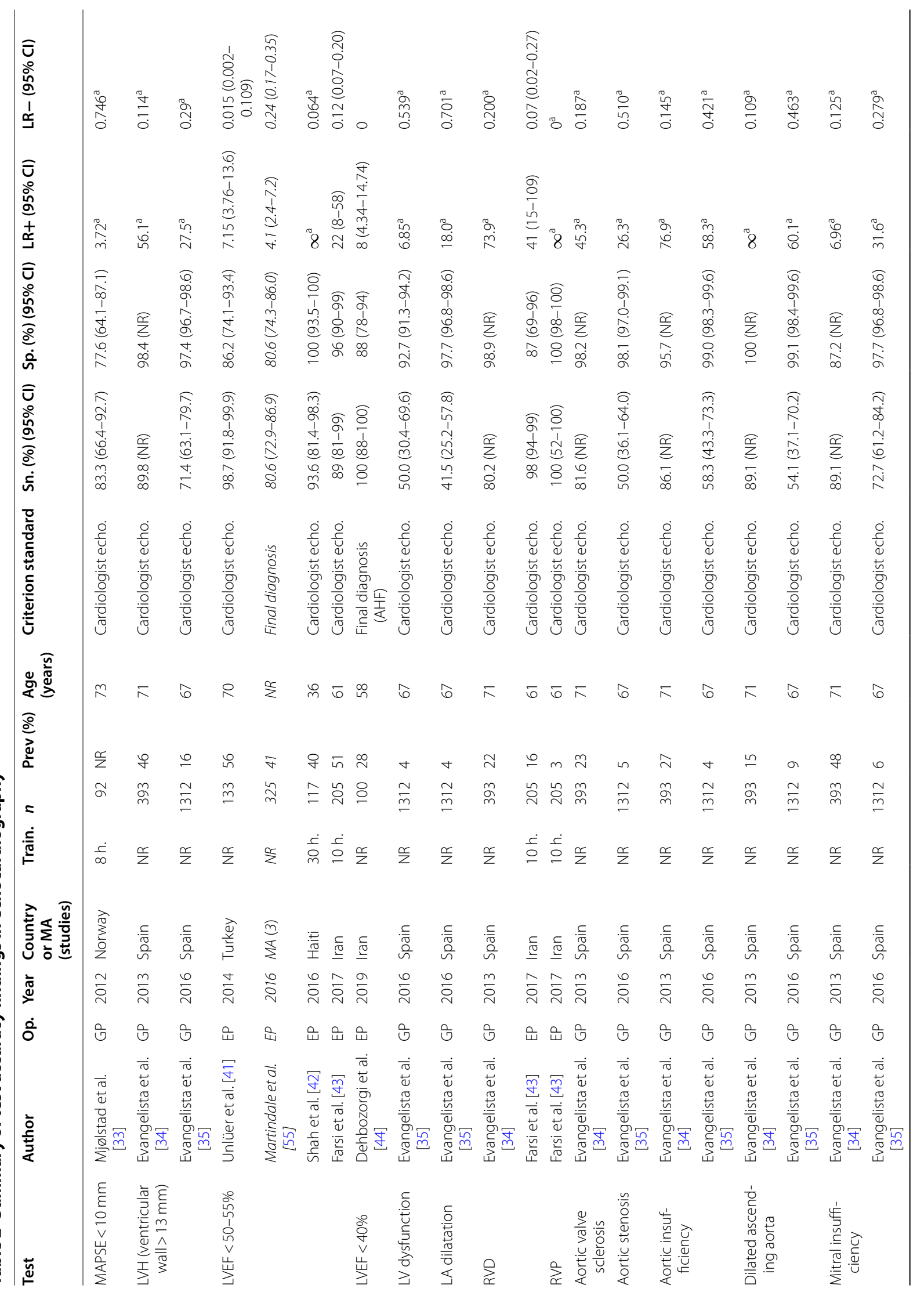




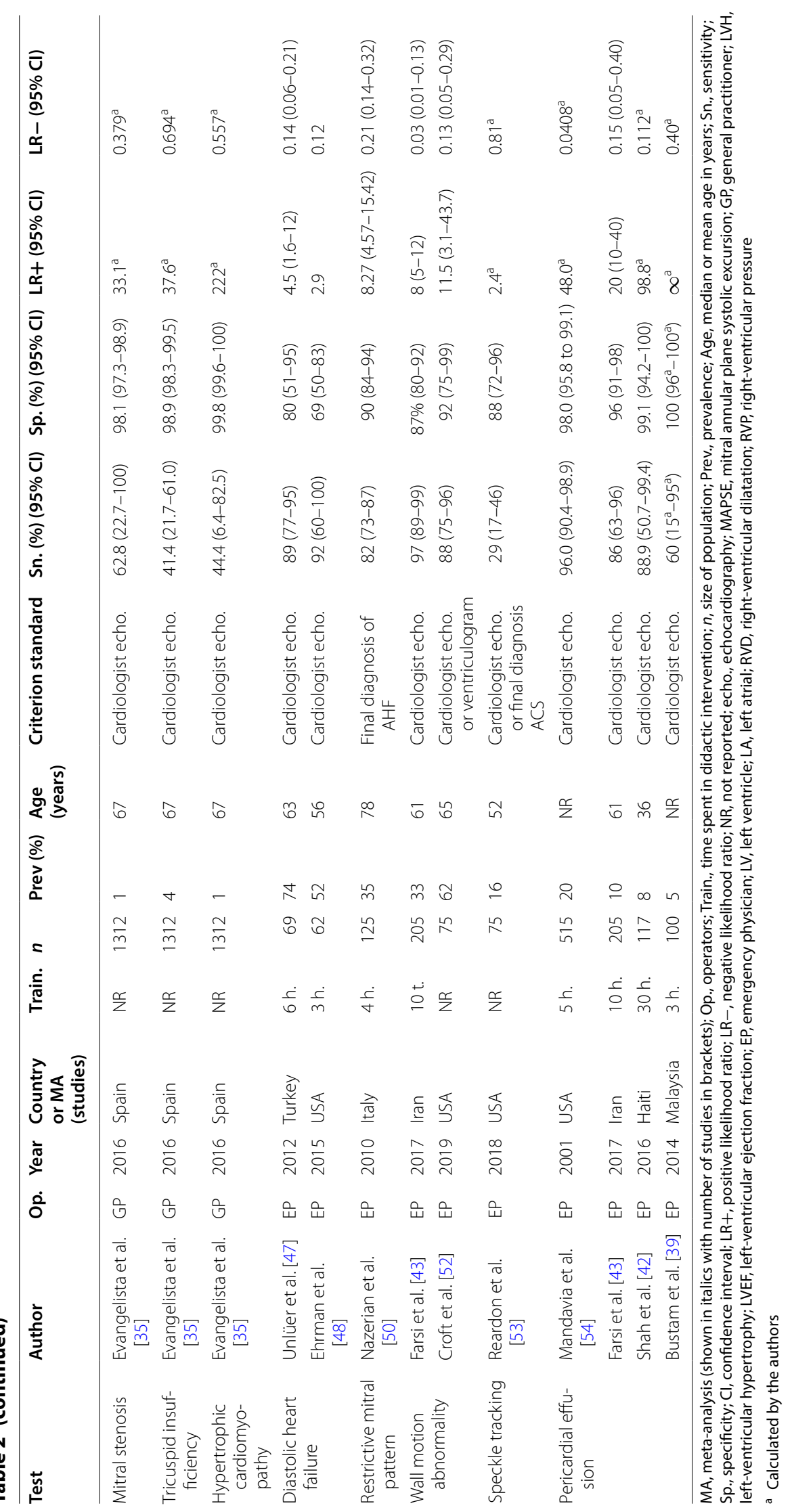




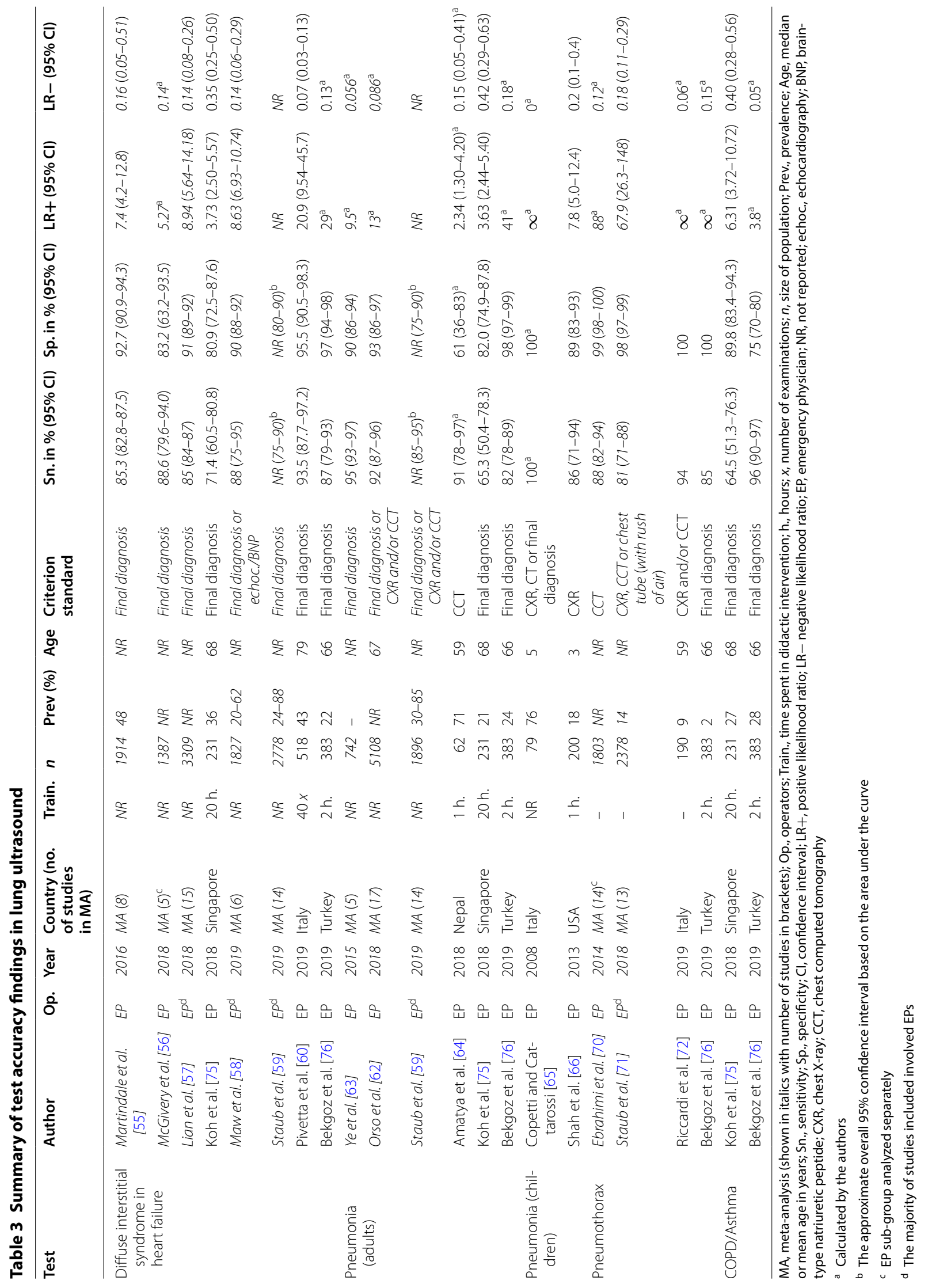




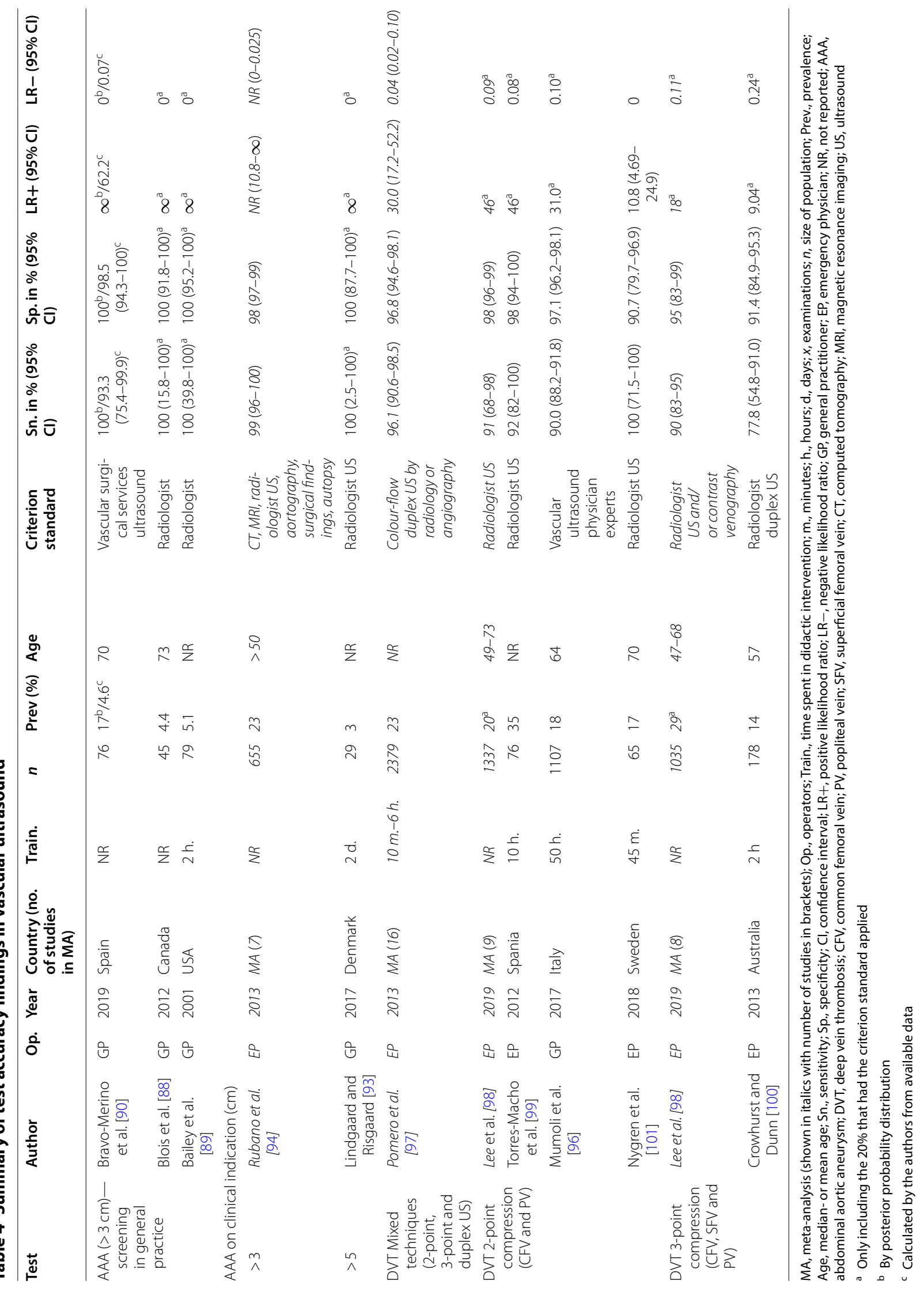




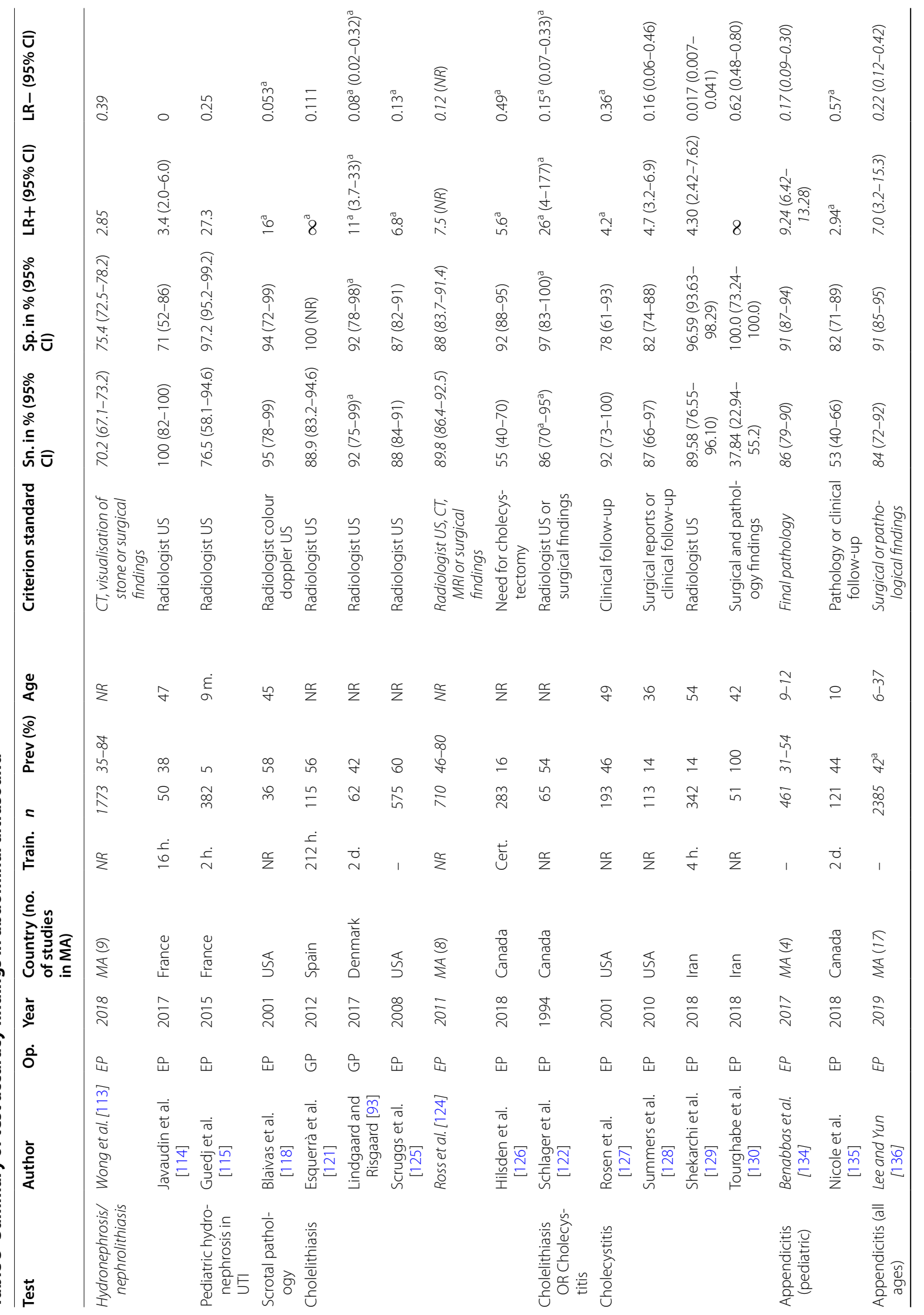




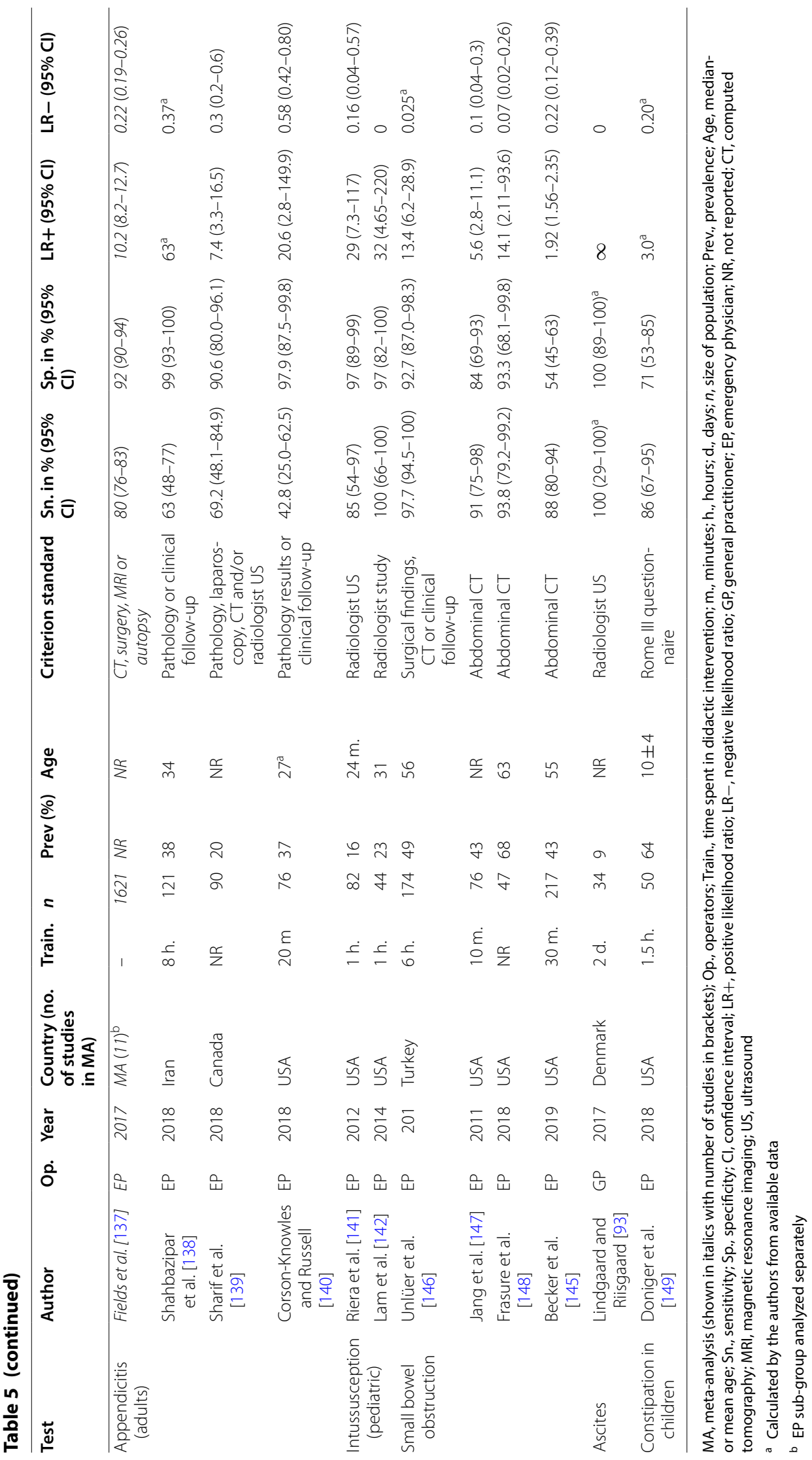




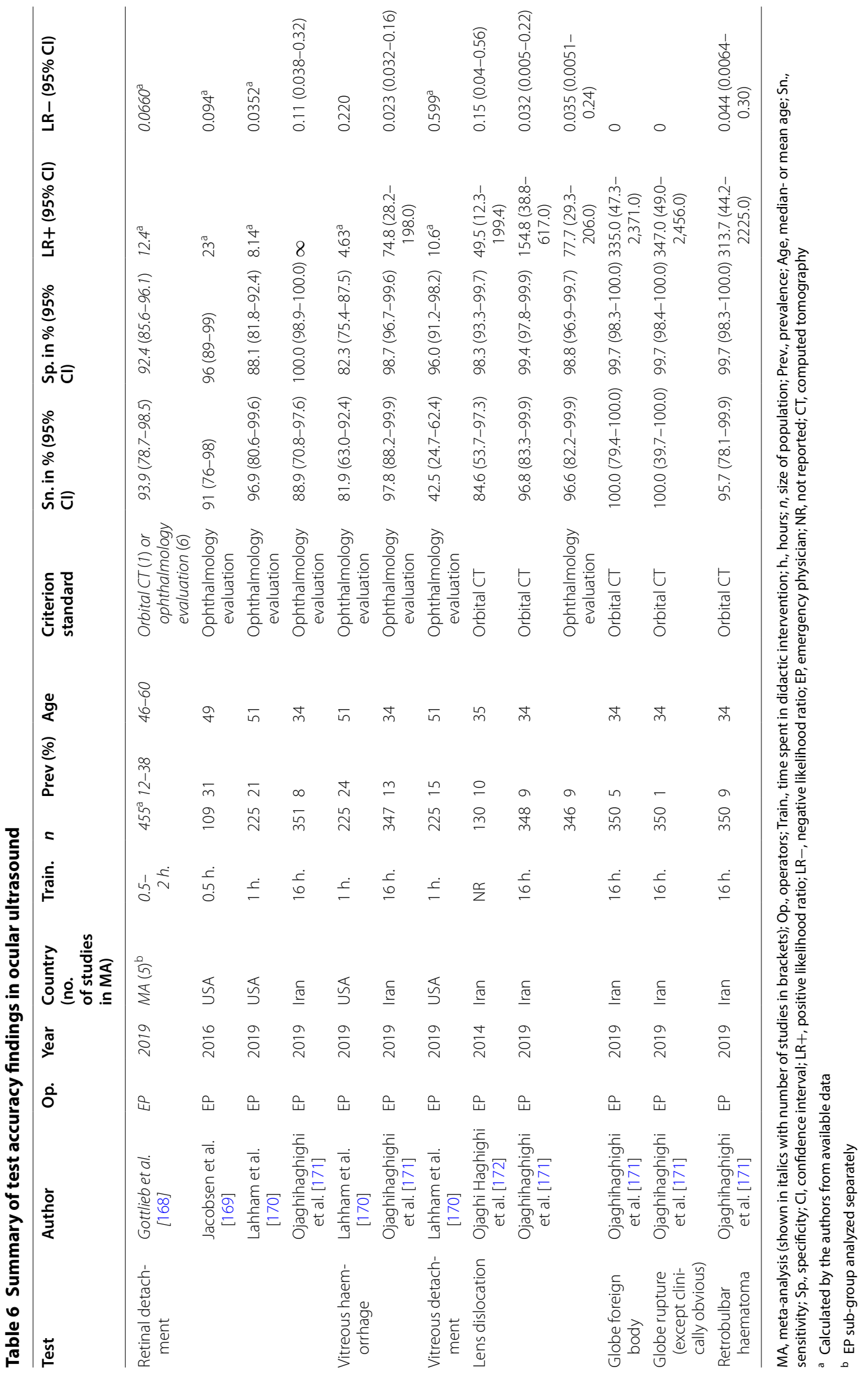




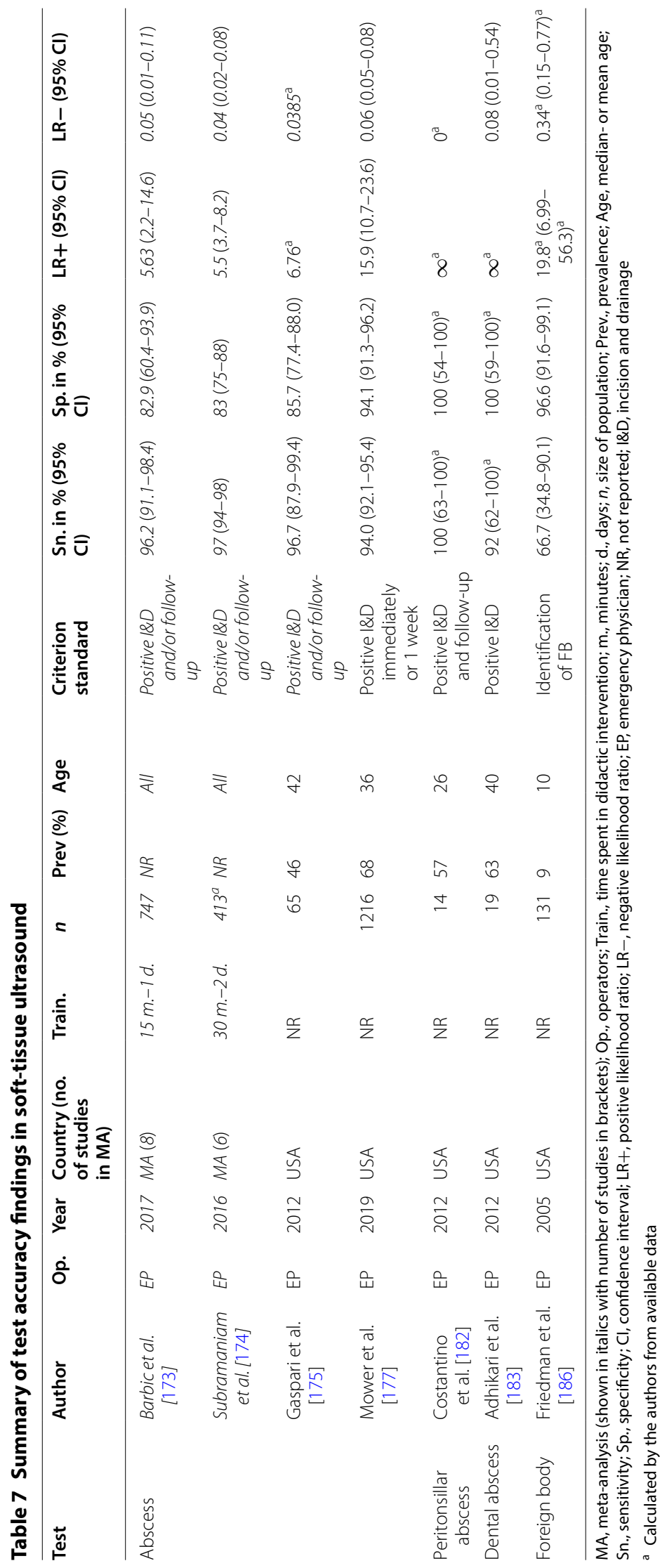




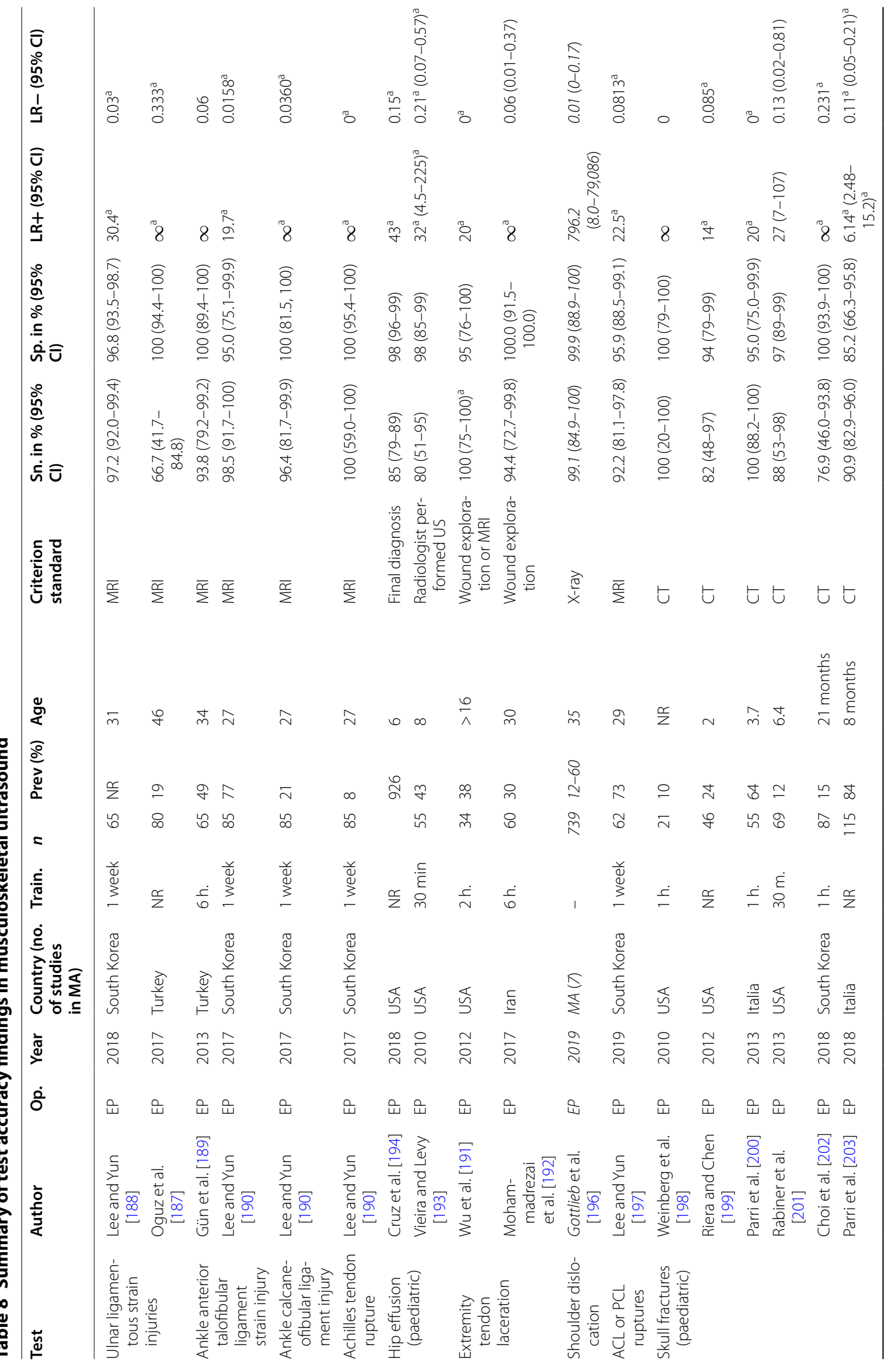




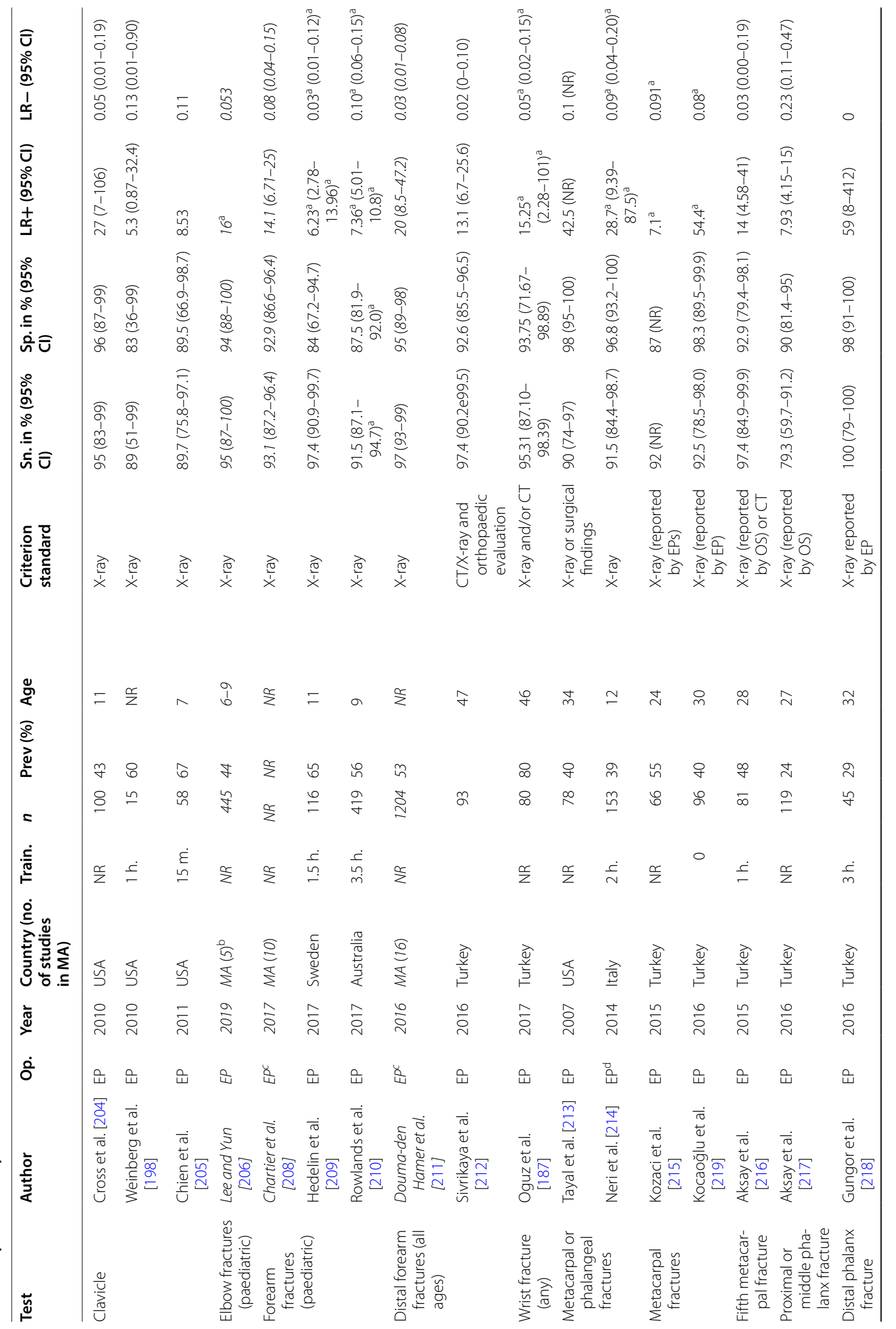




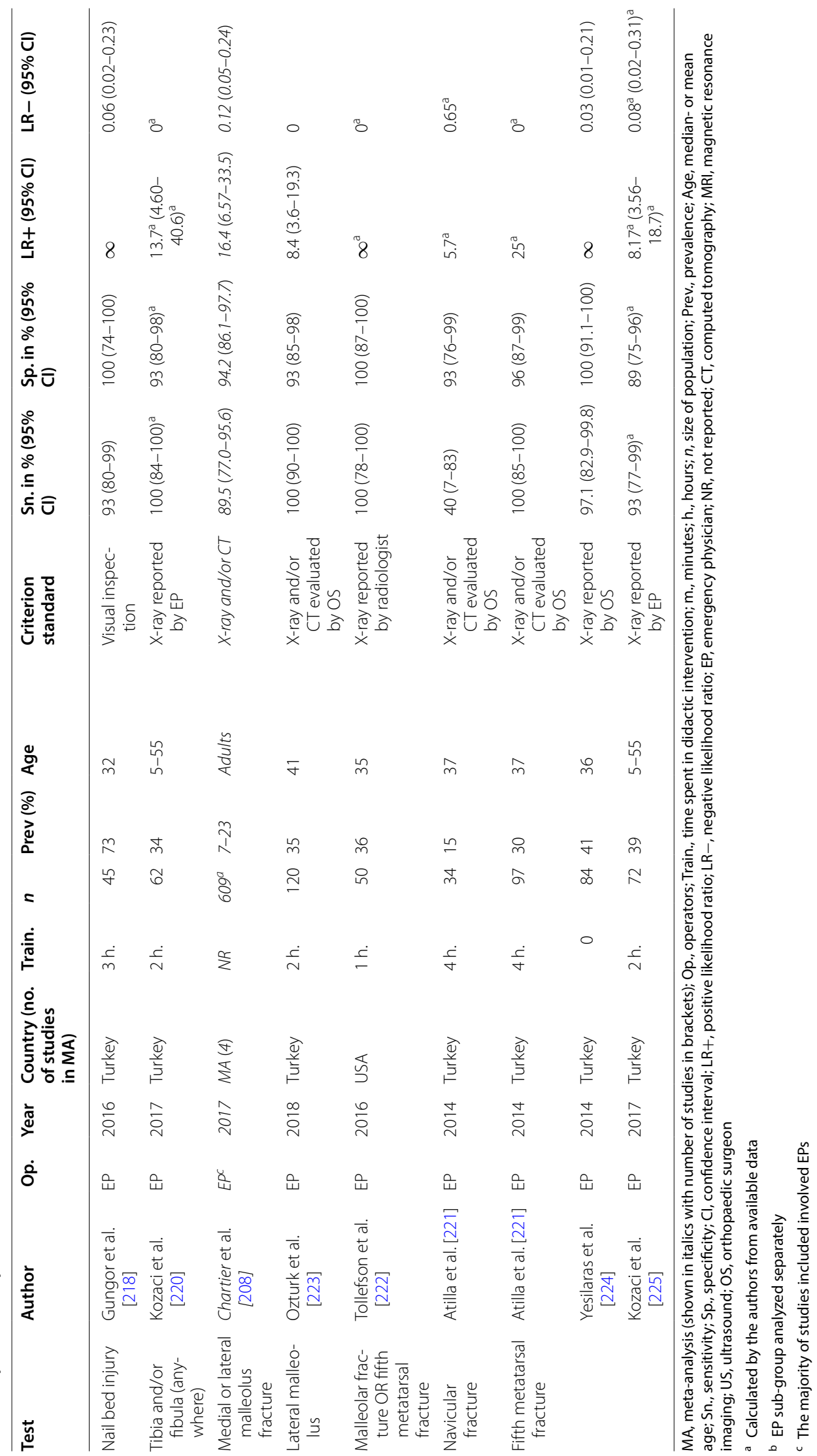


other clinical parameters for ADHF ever studied [55]. One meta-analysis only included studies where also chest X-ray (CXR) had been compared with LUS towards the same gold standard, and found that CXR had the same specificity (90\%) but lower sensitivity than LUS (73\% vs $88 \%$ ) [58]. A recent randomised-controlled study by Pivetta et al. [60], not analyzed in these meta-analyses, allocated patients after the initial suspicion of ADHF into groups receiving CXR and pro-brain natriuretic peptide (pro-BNP) or LUS, and found not only that LUS had both superior specificity and sensitivity compared to the criterion standard of final chart diagnosis, but also a shorter time to the diagnosis (5 min vs $104.5 \mathrm{~min}$ ). Finally, one Australian study analyzed inter-rater agreement between experienced and novice EP lung sonographers which was found to be good, with a Cohen's kappa coefficient of 0.70 [61].

Three meta-analyses were identified that assessed the accuracy of LUS in diagnosing pneumonia in unselected adult populations $[59,62,63]$. Orso et al. found 17 studies in ED populations where focal subpleural consolidations, focal B lines, or a combination of these were considered a positive finding, using X-ray and/or CT as the criterion standard, and found a pooled sensitivity of $92 \%$ and a specificity of $93 \%$, similar to the findings in the metaanalysis by Staub et al. [59]. Ye et al. [63] only included studies where LUS was directly compared to CXR using the final diagnosis as the criterion standard, and found that LUS had a sensitivity of $95 \%$ against $77 \%$ for CXR, while the specificity was the same, $90 \%$. A recent study not included in these meta-analyses found a similar superiority to CXR in a Nepalese ED population [64].

An Italian study on PoCUS for pneumonia in a paediatric population by one expert EP $(n=79)$ agreed with the final diagnosis of pneumonia in all cases and had no false-positive findings [65]. A later study in 200 children with suspected pneumonia (prevalence $=18 \%$ ) showed sensitivity and specificity of $86 \%$ and $89 \%$, respectively, when compared to CXR as the gold standard [66]. Ultrasound has been shown to be more sensitive than CXR in a study of a paediatric ED population, but less specific [67], and another study showed a 39\% reduction in use of CXR for the final diagnosis of pneumonia in children in a randomised trial, with no cases of missed diagnoses or complications [68]. PoCUS by paediatric EPs instead of CXR was in one study associated with less time spent and decreased overall costs [69].

The absence of pleural sliding and B lines is a sign of pneumothorax, and finding the point where the pleural layers separates from each other, the lung point, is pathognomonic. A recent meta-analysis showed a very high accuracy of PoCUS when performed by EPs, with $88 \%$ sensitivity and $99 \%$ specificity, and it was superior to CXR which had $46 \%$ sensitivity and $100 \%$ specificity [70]. The findings were similar in another recent meta-analysis, albeit with a somewhat heterogeneous operator group [71], as well as in a recent original prospective observational study [72].

Two studies from 2017 used the total cases of positive findings of rib fractures found by either LUS or CXR as the criterion standard (assuming that there were no falsepositive findings) and found a sensitivity of $81-98 \%$ in LUS compared to $41-53 \%$ for CXR [73, 74]. A third study found a similar concordance between LUS and CXR and/ or CCT [72].

Two studies evaluated the accuracy of PoCUS through present lung sliding and predominant $\mathrm{A}$ lines as a marker for asthma or chronic obstructive pulmonary disease (COPD) in the setting of dyspnoea, and found an LR+ of 3.8-6.3 and an LR- of 0.05-0.40 [75, 76]. Such LUS findings can also be seen in patients without pulmonary pathology, which may explain the poorer test characteristics seen in the undifferentiated ED populations compared to what has been seen in intensive-care unit populations [59].

Finally, we identified 11 articles which studied the impact of different PoCUS protocols on the overall diagnosis of patients presenting with undifferentiated respiratory or chest symptoms. An Italian ED-based study showed that LUS in the setting of pleuritic pain without dyspnoea had $97 \%$ sensitivity and $96 \%$ specificity for detecting lesions that did not show up on CXR, using other imaging modalities and final diagnosis as their criterion standard [77]. Another Italian study found that LUS in dyspnoeic patients changed the diagnosis in $44 \%$ of cases and altered management in 58\% [78]. Danish EPs evaluating dyspnoeic patients with PoCUS of heart, lung, and deep veins found life-threatening diagnoses that were missed in the primary assessment in $14 \%$ of patients, reporting a total of $100 \%$ sensitivity and $93 \%$ specificity for the diagnosis of such conditions [79]. The same group randomised 320 dyspnoeic patients (and $\mathrm{SpO} 2<95 \%$ ) into a PoCUS group or management as usual, and found as their primary endpoint a significant $24 \%$ higher accuracy in diagnosis at $4 \mathrm{~h}$ (88\% vs $64 \%)$, using masked audit as the gold standard [80]. Similarly, two studies found a significant reduction in time needed for diagnosis using integrated ultrasound on dyspnoeic patients [81, 82]. It has also been shown that the addition of heart and lung PoCUS allowed the EPs to reduce the number of diagnoses on their differential diagnosis list from 5 to $3(p<0.001)$ [83], and also three other studies showed statistical significance in PoCUS overall diagnostic accuracy in patients with dyspnoea [84-86]. One USA study could not show significant diagnostic or management changes when a PoCUS protocol was applied to dyspnoeic patients in ED significantly, but it improved EPs' confidence levels [87]. 


\section{Vessels}

Main test characteristic findings can be found in Table 4.

Screening for abdominal aortic aneurysms (AAA) by GPs would require a very high accuracy to avoid false positive in a relatively low pre-test probability population, even if one selects the population who is at risk, men who have smoked in the ages between 65 and 75. We identified three small studies of GPs' screening for AAA in such populations against a gold standard [88-90]. All found 100\% accuracy for AAA greater than $3 \mathrm{~cm}$ and concluded screening by GPs were feasible. One larger feasibility study only confirmed positive cases [91]. Hoffmann et al. [92] also found screening by EPs in the emergency department feasible, but requiring substantial resources for a low success rate.

In a Danish study, inexperienced GPs achieved 100\% accuracy for AAA $>5 \mathrm{~cm}$ compared to radiologists when the scan was performed on clinical indication [93]. Similarly, one meta-analysis showed that EPs have very high accuracy for detecting AAA $>3 \mathrm{~cm}$ compared to formal radiologist performed ultrasound when performed on indication [94].

One Japanese retrospective study investigated the impact of GPs screening of carotid intima media thickness in patients at risk of coronary artery disease (CAD) on later interventions, and found an increase in the prevalence of CAD in patients referred to a local specialist centre and higher probability of coronary angiograms and revascularization [95].

One multi-centre study assessed Italian GPs' accuracy of a two-point compression technique for the identification of lower extremity deep vein thrombosis (DVT) and found $90 \%$ sensitivity and $97 \%$ specificity compared to radiologist ultrasound [96]. A meta-analysis on EPs use of PoCUS for detection of DVT found even higher accuracy with a sensitivity of $96 \%$ and a specificity of $97 \%$ [97]. A newer meta-analysis from 2019 shows a pooled sensitivity of $91 \%$ and a specificity of $98 \%$ for the two-point compression technique (assessing the common femoral vein and the popliteal vein) and similarly $90 \%$ and $95 \%$ for the three-point compression technique (including the superficial femoral vein) [98]. Three other studies not analyzed in above meta-analyses show similar test accuracies [99101]. One study showed a $>4$-fold reduction in ED length of stay for the group with EP-performed DVT studies vs the radiology department patients [102].

Ultrasound-guided peripheral venous catheter (PVC) insertion has been shown in some studies to reduce time and attempts [103-105], while others show similar or even worse success rate [106-108]. One study found that ultrasound-guided PVC insertion was associated with a higher rate of extravasation, $3.6 \%$ vs $0.3 \%$ [109]. Another study showed a $73 \%$ success of cannulation of the brachial or the basilic vein after two failed attempts without ultrasound, but also showed an $8 \%$ rate of extravasation at $1 \mathrm{~h}$ [110]. One group evaluated EPs use of PoCUS before peripheral venous cannulation of children less than 7 years before cannulation as usual, and found visible veins on ultrasound a strong predictor for successful cannulation [111]. It has also been found that EPs could insert a standard 2.5-in., 18-gauge peripheral venous catheter in the internal jugular vein with a success rate of $97.1 \%$ after two failed attempts by management as usual by nursing staff [112].

\section{Abdomen}

The main findings on diagnostic test accuracy of abdominal PoCUS are listed in Table 5.

One meta-analysis of EPs' findings of hydronephrosis as a surrogate for nephrolithiasis in patients presenting with renal colic found only moderate sensitivity and specificity [113]. Moderate-to-severe hydronephrosis is highly specific for the presence of a stone at $94 \%$, but only with a sensitivity of $29 \%$. One study not included in this meta-analysis found $100 \%$ sensitivity, but moderate specificity [114]. A French study found that EPs correctly identified hydronephrosis in children with urinary tract infections (prevalence $=5 \%$ ) with a sensitivity of $76.5 \%$ and a specificity of $97.2 \%$ [115]. Finally, one large $(n=2759)$ study, randomising patients into diagnosis through EP PoCUS, radiologist ultrasound or computed tomography (CT), found no difference in highrisk diagnoses that could be due to missed or delayed diagnosis after 30 days, and showed overall lower cumulative radiation exposure at 6 months for both ultrasound groups compared to the CT group [116]. They also showed a slight, but significant, reduction in ED length of stay, while another study found halving of the length of stay [117].

Only one small, retrospective study reviewed EPs diagnostic accuracy of scrotal PoCUS, and found that the EPs correctly diagnosed epididymitis, orchitis, and testicular torsion in 35 of 36 cases [118]. No cases of testicular torsion were missed.

Two Norwegian studies demonstrated clinical usefulness for the use of GP operated PoCUS to demonstrate cholelithiasis already in the $80 \mathrm{~s}[119,120]$, and also a more recent study shows high agreement between GP and radiologist performed ultrasound [121]. In the ED setting, a high accuracy was shown already in a 1994 study [122] and Blaivas et al. [123] showed a significant reduction in the length of stay in the emergency department when EPs used PoCUS for diagnosis of biliary disease. One meta-analysis found an LR+ of 7.5 and LR - of 0.12 on EP-performed PoCUS for cholelithiasis [124], similar to a large, retrospective study not included in the meta-analysis [125]. A similar high specificity was found in a more recent study, and a sensitivity of 55\% when using eventual need for cholecystectomy as their 
gold standard [126]. When it comes to cholecystitis, the LR+ ranged from 4.2 to 4.7 and the LR - from 0.05 to 0.39 in three studies of varying design [127-129]. Summers et al. [128] found that there were close agreement with radiology department ultrasound when compared to the criterion standard of surgical reports and followup, and suggested that patients with negative EP scans are unlikely to require surgery. Another study could not conclude the same, as they, in contrast to the other studies, only found $38 \%$ sensitivity using surgical findings as the criterion standard [130]. The positive likelihood ratio was high nevertheless, as specificity in their study was $100 \%$. A Turkish study found that diagnosis and management were more likely to be affected if the clinician had moderate, rather than low or high, suspicion about the diagnosis prior to the study [131]. One study performed PoCUS on patients presenting with non-traumatic epigastric pain, and found a cholelithiasis prevalence of 39\% in this population, even though the treating EP did not initially consider the need for biliary ultrasound in $85 \%$ of these cases [132]. A USA study found that the presence of a dilated common bile duct on EP-performed PoCUS, in the absence of laboratory findings or signs of cholecystitis on ultrasound, was unlikely to be a good indicator for complicated biliary pathology (sensitivity $23.7 \%$ and specificity 77.9\%) [133].

Appendicitis has several hall-mark findings such as oedematous wall and overall thickness. One meta-analysis found an LR+ of 9.24 on EP-performed ultrasound for appendicitis in children [134], reproduced in one study published since [135]. Lee and Yun [136] found LR+ of 7.0 in a 2019 meta-analysis of PoCUS on all ages, while Fields et al. [137] found LR+ of 10.2 in their sub-group analysis of EP-performed PoCUS for appendicitis in a 2017 meta-analysis. The LR-, however, ranged from 0.17 to 0.22 , and one can conclude that EP-performed PoCUS is useful to rule in appendicitis, but not sufficient on its own to rule it out. This can also be concluded from the latest three studies not included in the above-mentioned meta-analyses [138-140].

Concentric rings on ultrasound of the small bowel indicate intussusception in children in whom one suspects this condition [141]. We identified one prospective observational study and one retrospective analysis of EP-performed PoCUS for intussusception after only short periods of training, both showing high specificities of 94-97\%, but varying sensitivities of $85-100 \%[141,142]$. One retrospective study was limited by its design giving an absence of true negative findings, but showed sensitivity of $79 \%$ in novices and $90 \%$ in a certified paediatric EP [143], while a South Korean group found that PoCUS significantly reduced the door-to-reduction time and overall stay in their ED [144].

Small bowel obstruction can be seen using ultrasound by identifying features such as small bowel dilation, abnormal peristalsis, small bowel wall oedema, and intraperitoneal free fluid [145]. Four studies in the ED showed sensitivities from 88 to $98 \%$ [145-148], with two studies showing a higher sensitivity, but lower specificity for EPs than for radiologist ultrasound when compared to CT $[146,147]$. One of the studies showed lower specificity than the other three studies (54\% vs $84-94 \%$ ), citing a shorter didactic session and experience requirements as a possible explanation [145].

One small study found that GPs had 100\% agreement with radiologists on the use of PoCUS for finding ascites on indication [93].

A small study $(n=50)$ compared ultrasound measured transverse diameter of the rectum against Roma III criteria for constipation in children, and found high sensitivity of $86 \%$, but a somewhat low specificity of $71 \%$ [149]. However, ultrasound was not less sensitive than abdominal X-ray (87\%) and trended towards being more specific (71\% vs $40 \%$ ). A rectal diameter of $3.8 \mathrm{~cm}$ or greater correlated well with constipation.

Two studies were identified using several of the above-mentioned techniques to help diagnose patients presenting with abdominal pain and found an overall improvement in diagnostic accuracy compared to workup as usual $[150,151]$.

\section{Obstetric ultrasound}

Inexperienced Danish GPs had 28 of 30 measurements of gestational age (GA) within 3 days of the obstetrician performed estimate, while the final 2 were within 7 days [93]. Johansen et al. [152] found that GP's measurements of GA in an 11 year period $(n=356)$ showed the same agreement with actual date of birth as did those of the local obstetric service $(n=14,550)$. The same agreement was found in six other GP studies between 1985 and 2001 [153-158].

Also EP measured crown-rump length (CRL), used in first trimester estimation of GA, showed in two studies correlation coefficients of 0.95-0.98 when compared with obstetric ultrasound $[159,160]$. Another study found that EPs were accurate stratifying GA into before and after 24 weeks, and thus foetal potential viability if one decides to go ahead with an emergent caesarean section in patients unable to give an accurate history due to lowered consciousness [161].

One meta-analysis assessed EPs' accuracy in diagnosing ectopic pregnancy by PoCUS, defining a positive finding as an empty uterus in a patient with a confirmed pregnancy [162]. Using this "safe" definition, the pooled sensitivity was high at $99.3 \%$, while the specificity ranged from 42 to $89 \%$, pooled specificity estimate not being possible to calculate due to study heterogeneity.

Another meta-analysis included six studies aimed to show whether EP-performed pelvic ultrasound on 
women with symptomatic early pregnancy in the ED caused a reduction in the length of stay (LOS) in the ED, and confirmed this, with a mean reduction in LOS of 74 min (95\% CI 49-99) [163].

Among those visiting ED due to bleeding in the first trimester, one study showed $42 \%$ had the expectation of getting confirmation of foetal viability by ultrasound and blood work [164]. In addition to identifying an intrauterine pregnancy, confirming foetal heart activity is decisive in diagnosing a threatened or missed abortion. We identified four studies where GPs had 100\% accuracy (total $n=295)[93,152,153,165]$ and one study of EPs showing a sensitivity of $89 \%$ and a specificity of $100 \%$ by use of transabdominal transducer [166]. In this study, mean GA was 9.5 weeks, and only the heart activity of the very earliest pregnancies was missed when compared to a radiologist using transvaginal transducer.

Two studies (total $n=387$ ) showed that both GPs and EPs had 100\% accuracy in detecting foetal position in the third trimester $[152,167]$.

\section{The eye}

Studies on ocular PoCUS are listed in Table 6. Retinal detachment may be seen on ultrasound as a hyperechoic line separating from the choroid while being tethered to the optic disc. One recent meta-analysis determined the test characteristics of ocular PoCUS for this condition [168]. A sub-group analysis of five studies where the provider was an EP working in the ED found a sensitivity of $94 \%$ and a specificity of $91 \%$. One retrospective study excluded from this meta-analysis, due to its retrospective design, showed similar numbers [169], as did two more recent prospective studies [170, 171] (see Table 6).

One study was identified estimated test accuracies for the important differential diagnoses of vitreous haemorrhage and detachment, and found high total accuracy for haemorrhage and high specificity for vitreous detachment [170]. Another study evaluated 232 patients (351 eyes) after trauma (excluding obvious globe rupture), and found high accuracy for the detection of vitreous haemorrhage, lens dislocation, globe foreign body, globe rupture, and retrobulbar haematoma [171]. The same group also found high accuracy for the detection of traumatic lens dislocation in a different study 5 years previously [172].

\section{Soft tissue}

Linear, high-frequency ultrasound can give detailed images of structures in the soft tissue, and findings from studies are summarized in Table 7. A 2017 meta-analysis included eight studies on adult and paediatric ED populations determining the accuracy of EPs using PoCUS to detect the presence of an abscess in patients presenting with signs of skin and soft-tissue infection, and found a pooled sensitivity of $96 \%$ and a specificity of $83 \%$ [173]. The pooled sensitivity of the paediatric sub-group was slightly lower at $94 \%$, but had the same specificity. The decision of whether to lance or not was changed in $14-56 \%$ of the cases. Pre-study teaching varied from 15 min to 1 day. A 2016 meta-analysis including six studies showed the same test accuracy [174]. Another study compared EP PoCUS and CT for abscesses head-to-head and found significantly better sensitivity for PoCUS (97\% vs $77 \%$ ), and similar specificity ( $86 \%$ vs $91 \%$ with overlapping 95\% confidence intervals) [175]. In a primary care outpatient setting, it has been showed that the size of abscesses was estimated incorrectly by clinical examination in $52 \%$ of cases and ultrasound changed management in $55 \%$ of cases [176]. One study compared the test accuracy of clinical examination with and without PoCUS on finding soft-tissue abscesses [177]. They found very high accuracy and no significant difference between the groups in the population for which the EP indicated that she was clinically certain about the diagnosis $(n=1111)$. However, in the uncertain cases $(n=105)$, ultrasound changed management in a quarter, appropriately so in $85 \%$ of these. Also in a paediatric ED population, it was found that ultrasound did not change the ED treatment failure rate, even though ultrasound changed management from surgical to medical or vice versa in $25 \%$ of cases [178]. This is in contrary to another study in a paediatric population who did see a significant reduction in failure rate, with three times higher failure rates in the non-PoCUS vs PoCUS groups (14\% vs 4\%) [179]. The same group found similar rates in adults $(n=125)$, with $17 \%$ vs $3.7 \%$, but the $95 \%$ confidence intervals showed $0-19.4 \%$ difference between the groups, leaving it barely statistically significant [180]. A US study showed that the ED length of stay was significantly reduced, by a mean of $73 \mathrm{~min}$, when patients received EP PoCUS rather than radiology ultrasound [181]. They also found significant differences in the two groups on incision and drainage rate which was twice as high in the PoCUS group and rate of ED intravenous antibiotics, which was $60 \%$.

Two small studies on the use of PoCUS for the detection of peritonsillar abscess [182] and dental abscess [183] showed near $100 \%$ test accuracy, but had wide confidence intervals due to small populations.

Two studies $(n=27$ and $n=75)$ evaluated EP PoCUS diagnostic accuracy on paediatric soft-tissue neck masses and found a Cohen's kappa coefficient when compared to the final diagnosis of 0.69 (95\% CI 0.44-0.94) and 0.71 $(0.60-0.83)$, respectively $[184,185]$.

One clinical study on the use of PoCUS for identification of soft-tissue foreign bodies showed that ultrasound identified two-thirds of all foreign bodies with a specificity of $97 \%$ [186]. There were no significant differences in performance characteristics of X-ray which showed sensitivity of $58 \%$ and a specificity of $90 \%$. 


\section{Musculoskeletal ultrasound}

The retrieved studies on musculoskeletal ultrasound were on the ability to detect acute tendon trauma, joint fluid, shoulder dislocation, and bone fractures, and the test accuracy findings are summarized in Table 8.

Two studies studied the accuracy of EP-performed PoCUS on suspected ligamentous injuries in the ulnar part of the wrist and showed high specificity, but mixed sensitivity $[187,188]$, using magnetic resonance imaging (MRI) as the criterion standard. Two studies evaluating the same in the ankle showed high test accuracies against the same Ref. $[189,190]$. A US study showed a higher specificity for ligamentous laceration on extremity penetrating trauma than clinical examination without ultrasound when compared to surgical exploration or MRI [191], and this study and an Iranian study [192] showed $94-100 \%$ sensitivity and specificity.

Two studies showed high specificity (both 98\%) for paediatric hip effusions, but a somewhat reduced sensitivity of $80-85 \%$, compared to a chart review or radiologist performed ultrasound [193, 194]. One study showed that $50 \%$ of planned joint aspirations were avoided after PoCUS of swollen joints [195].

One meta-analysis on the use of PoCUS on patients with shoulder dislocations included seven studies $(n=739)$, and showed $99.1 \%$ sensitivity and $99.8 \%$ specificity when compared to X-ray [196]. The accuracy was similar for associated fractures, but one could not determine the clinical significance due to wide confidence intervals.

A South Korean study found high accuracy for the detection of anterior and posterior cruciate ligament tears by PoCUS [197].

Finding or excluding a bony fracture could be a useful utility of ultrasound in a GP setting given a high enough accuracy, as X-ray is usually not immediately available and may require significant travelling for the patient. We identified three meta-analyses and 25 primary studies evaluating the test accuracy of EP-performed ultrasound on different fractures, all summarized in Table 8. The main finding is that there is generally a very high sensitivity and specificity for detecting the cortical disruption representing the fracture ultrasound, but less for fractures near joints.

Six diagnostic accuracy studies on the use of EP-performed PoCUS to detect paediatric skull fractures found sensitivities ranging from 77 to 100 and specificities from 85 to 100 [198-203].

Clavicular fractures were studied in three studies, all showing high accuracy $[198,204,205]$, with false-negative cases being clinically non-significant green-stick fractures.

One meta-analysis of ultrasound for elbow fractures included a sub-group analysis of five studies where the operators were EPs, and showed a specificity of $95 \%$ and a sensitivity of 94\% [206]. Elbow fractures can be identified on ultrasound by cortical disruption and/or posterior fat pad sign. The latter is rare in radial head subluxation without fractures according to a US study, indicating that PoCUS may be an adequate rule out test before reduction of the subluxation [207].

One meta-analysis assessed the test characteristics of ultrasound to detect paediatric forearm fractures [208] and found sensitivity and specificity of 93, and also two studies published since showed high accuracy [209, 210]. Another meta-analysis, also including studies with adults, showed even higher accuracy with a pooled sensitivity of $97 \%$ and a specificity of $95 \%$ [211], and also showed no significant accuracy differences between inexperienced and experienced physicians. A Turkish study published after this metaanalysis has shown similar test accuracy in adults [212].

Studies on metacarpal and phalangeal fractures showed sensitivities ranging from 79 to $100 \%$ and specificities from 87 to $98 \%$, with the poorest accuracy for periarticular fractures and for the third and fourth metacarpal bones which are only available to scan from two surfaces [213-219]. The study of the distal phalanx fractures also assessed the accuracy of PoCUS to detect nail bed injuries before lifting the nail and visually inspecting, and found a $93 \%$ sensitivity and $100 \%$ specificity for this [218].

One study aimed to determine the combined accuracy for any tibia or fibula fracture, and found $100 \%$ sensitivity and $93 \%$ specificity against X-ray, and also found that all false positives were true positives when compared to $\mathrm{CT}$, indicating a higher accuracy than X-ray [220].

One study showed poor sensitivity for navicular bone fracture [221].

One meta-analysis from 2017 [208] and two more recent studies [222, 223] all showed high accuracy in detection of fractures in the ankle malleoli. Three studies determined the accuracy of PoCUS specifically for fifth metatarsal fracture, and found total accuracies in the $90 \mathrm{~s}$ [221, 224, 225].

\section{Discussion \\ Strengths and limitations}

This review is based on a search strategy that was designed to be comprehensive and sensitive enough to identify all relevant meta-analyses and primary research papers available, and included studies written in English, Spanish, Norwegian, and Swedish. In addition, reference lists of included studies were manually searched to identify further studies to include. However, the search only included searches through PubMed/MEDLINE, not EMBASE or similar proprietary databases. The main screening was only performed by one of the authors, which could be a source of bias.

One comprehensive systematic review only including clinical studies on the training and use of PoCUS by GPs already exists [12]. Given the scarcity of data, it was difficult 
to draw conclusions other than PoCUS has a potential of being a valuable tool for the general practitioner. A strength of our review is the wealth of data on GP relevant indications which we draw on from our EP colleagues. However, this may be one of the main weaknesses as well, as even though there is a considerable overlap in knowledge and skill bases, generalist approach, and even populations, there are also considerable differences. GPs tend to work more independently with less possibility of daily peer interaction, and have a broader scope of practice, not only including working with patients with conditions which require immediate action. In areas where patients can self-refer to emergency departments staffed by EPs, the pre-test probability of any given diagnosis will be different, with a skew towards more life-threatening conditions in EDs compared to those presenting to primary care run services. However, in other regions, where GPs may, indeed, be the first responder to any emergency, this may not be the case.

Nevertheless, much of a GP's evidence-based practice, is, and will likely always be, based on work done in other fields. In fact, there are most likely relevant studies on the use of ultrasound done by, e.g., physiotherapist, sports medicine physicians, paediatricians, internal medicine specialist, surgeons, etc., which also could be relevant for GPs.

The studies identified were heterogenous and ranged from small pilot studies, through prospective and retrospective convenience sample observational studies, some randomised control trials and on to large, rigorous metaanalyses. In terms of operators, they include in some cases one expert GP or EP sonographer, while, in other cases, the operators were many, of different levels of experience, including novices, all only receiving short, specific didactic interventions. There were no attempts at formally assessing the quality of the primary studies by available quality assessment tools, but most of the meta-analyses will have had such assessment done by their respective authors.

Being a very heterogenous group of physicians, it is hard to establish an absolute list of possible indications for which any given GP may find PoCUS of clinical relevance. We think that we have created an overview where most GPs can find some areas of interest, but also acknowledge that others may criticise the exclusion of indications listed in Appendix 1.

\section{Conclusions}

This systematic review shows that ultrasound, at the point of care, is increasingly being utilised by GPs and EPs across the world. It also shows that generalists can, given a certain level of pre-test probability, safely use ultrasound in a wide range of clinical settings to aid diagnosis. For many conditions, the sensitivity is high and can help the physician rule out a condition, while for others, the specificity is high, helping to rule in a diagnosis. For some conditions, the total test accuracy is high, and it may, in fact, be a valuable screening tool. For some conditions, such as identifying foreign bodies and in shoulder dislocations, PoCUS seems to have similar accuracy as X-ray, while for others, such as rib fractures, tibia and fibula fractures, pneumothorax, pneumonia, and in patients presenting with pleuritic pain of any cause, it seems to outperform conventional X-ray. PoCUS has also shown to decrease the length of time to diagnosis and discharge in some settings, decrease failure rates of treatment, and to aid in difficult intravenous access.

GPs are by no means a homogenous group of physicians, neither are EPs. It is likely that if many EPs can learn to safely use clinical ultrasound, so can many interested GPs, as both groups are trained and used to applying a wide range of methods to assess a wide range of patients and conditions. It is likely that the patient population will vary from GP to GP as well, as we all work in different regions with populations of different disease prevalence profiles and health service seeking behaviors. It is important for both GPs and EPs to be aware of one's population's characteristics and pre-test probabilities for any given condition with regards to all aspects of clinical work, including history taking, examination, and diagnostic studies. Given the varying prevalence in each clinician's population, we, therefore, encourage the use of the likelihood ratios using Fagan's nomogram [226], which as a pre-requisite for usage only requires an estimate of pre-test likelihood rather than having the exact same prevalence as in the respective studies from which the data were obtained.

This systematic review will potentially be a valuable reference for physicians searching for evidence for the use of PoCUS in their given primary care setting. Even though most of the studies involved ultrasound performed by EPs, we believe what has been found is relevant also in a GP setting, and is, to date, the best evidence available. We hope also that our review can be of value in showing the need for further research in a primary care setting, and we see a need for more rigorous study designs, with more studies with multi-centre, randomised and controlled designs.

\footnotetext{
Abbreviations

AAA: abdominal aortic aneurysm; ADHF: acute decompensated heart failure; CAD: coronary artery disease; COPD: chronic obstructive pulmonary disease; CRL: crown-rump length; CT: computed tomography; CXR: chest X-ray; DVT: deep vein thrombosis; ED: emergency department; EP: emergency physician; GA: gestational age; GP: general practitioner/family physician; LOS: length of stay; LR+: positive likelihood ratio; LR-: negative likelihood ratio; LUS: lung ultrasound; LVEF: left-ventricular ejection fraction; LVH: left-ventricular hypertrophy; MAPSE: mitral annular plane systolic excursion; MeSH: medical subject headings; $\mathrm{MRI}$ : magnetic resonance imaging; $\mathrm{OOH}$ : out-of-hours; PoCUS: point-of-care ultrasound; pro-BNP: pro-brain natriuretic peptide; PVC: peripheral venous catheter.
}

Acknowledgements Not applicable. 


\section{Authors' contributions}

BS is the corresponding author. Both BS and SH collaboratively conceived, designed the study, and wrote the manuscript. BS performed the search and screened the articles. Both authors read and approved the final manuscript.

\section{Authors' information}

Bjarte Sorensen: BSc(Med) MB BS, Specialist in General Practice (Norwegian certification), Fellow of the Royal Australian College of General Practitioners (FRACGP), Hjelmeland General Practice Surgery, Prestagarden 13, 4130 Hjelmeland, Norway

Steinar Hunskaar: MD PhD, Specialist in General Practice (Norwegian certification), Professor at the Department of Global Public Health and Primary Care, University of Bergen, Bergen, Norway and Vice Dean of Education at the Faculty of Medicine, University of Bergen. Senior Researcher at the National Centre for Emergency Primary Health Care, NORCE Norwegian Research Centre AS, Bergen, Norway.

\section{Funding}

BS received a stipend from The Norwegian Committee on Research in General Practice, A board in Norwegian College of General Practitioners to work on the article. They requested broadly a systematic review on the use of ultrasound in general practice, but had no role in the design of the study nor in the collection, analysis, or interpretation of data and in writing the manuscript.

\section{Availability of data and materials}

The data sets generated during and/or analyzed during the current study are available from the corresponding author on reasonable request.

\section{Ethics approval and consent to participate}

Not applicable.

\section{Consent for publication}

Not applicable.

\section{Competing interests}

The authors declare that they have no competing interests.

\section{Author details}

${ }^{1}$ Hjelmeland General Practice Surgery, Prestagarden 13, 4130 Hjelmeland, Norway. ${ }^{2}$ Department of Global Public Health and Primary Care, University of Bergen, Bergen, Norway. ${ }^{3}$ National Centre for Emergency Primary Health Care, NORCE Norwegian Research Centre AS, Bergen, Norway.

\section{Appendix 1}

See Table 9.

\section{Table 9 Indications excluded due to less relevance for general practice}

\begin{tabular}{|c|c|}
\hline Organ & Indication \\
\hline Heart & $\begin{array}{l}\text { Echocardiography during resuscitation } \\
\text { Paediatric echocardiography }\end{array}$ \\
\hline Lungs & $\begin{array}{l}\text { Thoracic aortic aneurysm } \\
\text { Pulmonary embolism }\end{array}$ \\
\hline Vessels & $\begin{array}{l}\text { Type A dissection of the ascending aorta } \\
\text { Ruptured abdominal aortic aneurysm }\end{array}$ \\
\hline Abdomen and pelvis & $\begin{array}{l}\text { Hepatic abscess } \\
\text { Tubo-ovarian abscess } \\
\text { Pneumonperitoneum } \\
\text { Mesenteric ischemia }\end{array}$ \\
\hline Central nervous system & $\begin{array}{l}\text { Ventriculoperitoneal shunt malfunction } \\
\text { Intracranial pressure through optic nerve sheath diametre } \\
\text { Transcranial ultrasound for MCA perfusion }\end{array}$ \\
\hline Trauma & $\begin{array}{l}\text { Focused abdominal sonography in trauma (FAST)/extended FAST (eFAST) } \\
\text { Hemothorax } \\
\text { Pelvic fracture }\end{array}$ \\
\hline Procedures & $\begin{array}{l}\text { Regional nerve blocks } \\
\text { Closed reduction of fractures under sedation } \\
\text { Intubation } \\
\text { Pericardiocentesis } \\
\text { Neonatal intracranial bleeding } \\
\text { Lumbar puncture } \\
\text { Nasogastric tube placement verification } \\
\text { Cystostomy }\end{array}$ \\
\hline Others & $\begin{array}{l}\text { Undifferentiated hypotension/dehydration } \\
\text { Studies from prehospital emergency medical services } \\
\text { Mass casualty trauma triage } \\
\text { Gastric content }\end{array}$ \\
\hline
\end{tabular}




\section{Appendix 2}

\section{Ultrasound and general practice (MeSH terms)}

"ultrasonography"[MeSH Terms] AND ("primary health care"[MeSH Terms] OR "general practice"[MeSH Terms] OR "general practitioners" [MeSH Terms] OR "physicians, primary care"[MeSH Terms] OR "physicians, family"[MeSH Terms])

\section{Ultrasound and emergency medicine (MeSH terms)}

"ultrasonography"[MeSH Terms] AND ("emergency medical services"[MeSH Terms] OR "emergency treatment"[MeSH Terms] OR "emergency medicine" [MeSH Terms] OR “emergencies"[MeSH Terms])

\section{Ultrasound and general practice (keywords)*}

((((() ultrasonography) OR pocus) OR ultrasound $))$ OR echocardiography) $)$ AND (((((primary care physician $))$ OR (family practice)) OR (primary health care)) OR (family physician)) OR ((general practice) OR general practitioner))

automatically expanded by PubMed to ((('“diagnostic imaging"[Subheading] OR ("diagnostic"[All Fields] AND "imaging"[All Fields]) OR "diagnostic imaging"[All Fields] OR "ultrasonography"[All Fields] OR "ultrasonography"[MeSH Terms]) OR pocus[All Fields]) OR ("diagnostic imaging"[Subheading] OR ("diagnostic"[All Fields] AND "imaging"[All Fields]) OR "diagnostic imaging"[All Fields] OR "ultrasound"[All Fields] OR "ultrasonography"[MeSH Terms] OR "ultrasonography"[All Fields] OR "ultrasound"[All Fields] OR “ultrasonics”[MeSH Terms] OR "ultrasonics"[All Fields])) OR ("echocardiography"[MeSH Terms] OR "echocardiography"[All Fields])) AND ((((“physicians, primary care"[MeSH Terms] OR ("physicians"[All Fields] AND "primary"[All Fields] AND "care"[All Fields]) OR "primary care physicians"[All Fields] OR ("primary"[All Fields] AND "care"[All Fields] AND "physician"[All Fields]) OR "primary care physician"[All Fields]) OR ("family practice"[MeSH Terms] OR ("family"[All Fields] AND "practice"[All Fields]) OR "family practice"[All Fields])) OR ("primary health care"[MeSH Terms] OR ("primary"[All Fields] AND "health"[All Fields] AND "care"[All Fields]) OR "primary health care"[All Fields])) OR ("physicians, family"[MeSH Terms] OR ("physicians"[All Fields] AND "family"[All Fields]) OR "family physicians"[All Fields] OR ("family"[All Fields] AND "physician"[All Fields]) OR "family physician"[All Fields])) OR (("general practice"[MeSH Terms] OR ("general"[All Fields] AND "practice"[All Fields]) OR "general practice"[All Fields]) OR ("general
practitioners"[MeSH Terms] OR ("general"[All Fields] AND "practitioners"[All Fields]) OR "general practitioners"[All Fields] OR ("general"[All Fields] AND "practitioner"[All Fields]) OR "general practitioner"[All Fields])))

\section{Ultrasound and emergency medicine (keywords)*}

((()((emergency medical services) OR emergency medicine) OR emergency treatment) OR emergency physician) OR prehospital medicine)) AND (((ultrasound)) OR (((ultrasonography) OR pocus) OR echocardiography))

automatically expanded by PubMed to

((((“"emergency medical services”[MeSH Terms] OR ("emergency"[All Fields] AND "medical"[All Fields] AND "services"[All Fields]) OR "emergency medical services"[All Fields]) OR ("emergency medicine"[MeSH Terms] OR ("emergency"[All Fields] AND "medicine"[All Fields]) OR "emergency medicine"[All Fields])) OR ("emergency treatment"[MeSH Terms] OR ("emergency"[All Fields] AND "treatment"[All Fields]) OR “emergency treatment”[All Fields])) OR (("emergencies"[MeSH Terms] OR "emergencies"[All Fields] OR "emergency"[All Fields]) AND ("physicians"[MeSH Terms] OR "physicians"[All Fields] OR "physician”[All Fields]))) OR (prehospital[All Fields] AND ("medicine"[MeSH Terms] OR "medicine"[All Fields]))) AND ((“diagnostic imaging"[Subheading] OR ("diagnostic"[All Fields] AND "imaging"[All Fields]) OR "diagnostic imaging"[All Fields] OR "ultrasound"[All Fields] OR "ultrasonography"[MeSH Terms] OR "ultrasonography"[All Fields] OR "ultrasound"[All Fields] OR "ultrasonics"[MeSH Terms] OR “ultrasonics”[All Fields]) OR (((“diagnostic imaging"[Subheading] OR ("diagnostic"[All Fields] AND "imaging"[All Fields]) OR "diagnostic imaging"[All Fields] OR "ultrasonography"[All Fields] OR "ultrasonography"[MeSH Terms]) OR pocus[All Fields]) OR ("echocardiography" [MeSH Terms] OR "echocardiography"[All Fields])))

* To exclude indexed articles (which presumably were found by searching with $\mathrm{MeSH}$ terms) the keyword searches was done with the following filter:

((publisher[sb] NOT pubstatusnihms NOT pubstatuspmcsd NOT pmcbook) OR inprocess[sb] OR pubmednotmedline[sb] OR ((pubstatusnihms OR pubstatuspmcsd) AND publisher[sb])) OR pubmednotmedline[sb] 


\section{((publisher[sb] NOT pubstatusnihms NOT pubsta- tuspmcsd NOT pmcbook) OR pubmednotmedline[sb] OR ((pubstatusnihms OR pubstatuspmcsd) AND publisher[sb])) inprocess[sb]}

Received: 20 June 2019 Accepted: 21 October 2019 Published online: 19 November 2019

\section{References}

1. Moore CL, Copel JA (2011) Point-of-care ultrasonography. N Engl J Med 364(8):749-757

2. Weile J, Brix J, Moellekaer AB (2018) Is point-of-care ultrasound disruptive innovation? Formulating why POCUS is different from conventional comprehensive ultrasound. Crit Ultrasound J 10(1):25

3. Huibers L, Giesen P, Wensing M, Grol R (2009) Out-of-hours care in western countries: assessment of different organizational models. BMC Health Serv Res 9:105

4. Pandit T, Ray R, Sabesan S (2019) Review article: Managing medical emergencies in rural Australia: a systematic review of the training needs. Emerg Med Australas 31(1):20-28

5. Bosco C, Oandasan I (2016) Review of family medicine within rural and remote Canada: education, practice, and policy. The College of Family Physicians of Canada, Mississauga

6. Nieber T, Hansen EH, Bondevik GT (2007) Organization of Norwegian out-of-hours primary health care services. Tidsskr Nor Laegeforen 127:1335-1338

7. St John and the PRIME programme. https://www.stjohn.org.nz/Whatwe-do/Community-programmes/Partnered-programmes/PRIME/. Accessed 9 Sept 2019

8. Lopez DG, Hamdorf JM, Ward AM, Emery J (2006) Early trauma management skills in Australian general practitioners. ANZ J Surg 76(10):894-897

9. Huibers LAMJ, Moth G, Bondevik GT, Kersnik J, Huber CA, Christensen MB, Leutgeb R, Casado AM, Remmen R, Wensing M (2011) Diagnostic scope in out-of-hours primary care services in eight European countries: an observational study. BMC Fam Pract 12:30

10. Hall JWW, Holman H, Bornemann P, Barreto T, Henderson D, Bennett K, Chamberlain J, Maurer DM (2015) Point of care ultrasound in family medicine residency programs: a CERA study. Fam Med 47(9):706-711

11. Bornemann P, Barreto T (2018) Point-of-care ultrasonography in family medicine. Am Fam Physician 98(4):200-202

12. Andersen CA, Holden S, Vela J, Rathleff MS, Jensen MB (2019) Point-ofcare ultrasound in general practice: a systematic review. Ann Fam Med 17(1):61-69

13. Myhr K, Sandvik H, Morken T, Hunskaar S (2017) Point-of-care ultrasonography in Norwegian out-of-hours primary health care. Scand J Prim Health Care 35(2):120-125

14. Mengel-Jørgensen T, Jensen MB (2016) Variation in the use of pointof-care ultrasound in general practice in various European countries. Results of a survey among experts. Eur J Gen Pract 22(4):274-277

15. Flynn CJ, Weppler A, Theodoro D, Haney E, Milne WK (2012) Emergency medicine ultrasonography in rural communities. Can J Rural Med 17(3):99-104

16. Léger P, Fleet R, Maltais-Giguère J, Plant J, Piette É, Légaré F, Poitras J (2015) A majority of rural emergency departments in the province of Quebec use point-of-care ultrasound: a cross-sectional survey. BMC Emerg Med 15:36

17. Leschyna M, Hatam E, Britton S, Myslik F, Thompson D, Sedran R, VanAarsen K, Detombe S (2019) Current state of point-of-care ultrasound usage in Canadian emergency departments. Cureus 11(3):e4246

18. Bobbia X, Zieleskiewicz L, Pradeilles C, Hudson C, Muller L, Claret PG, Leone M, de La Coussaye J-E, Winfocus France Group (2017) The clinical impact and prevalence of emergency point-of-care ultrasound: a prospective multicenter study. Anaesth Crit Care Pain Med 36(6):383-389

19. Bobbia X, Abou-Badra M, Hansel N, Pes P, Petrovic T, Claret PG, Lefrant JY, de La Coussaye JE, Winfocus France Group (2017) Changes in the availability of bedside ultrasound practice in emergency rooms and prehospital settings in France. Anaesth Crit Care Pain Med 37(3):201-205

20. Nielsen K, Lauridsen JRM, Laursen CB, Brabrand M (2015) Physicians using ultrasound in Danish emergency departments are mostly summoned specialists. Scand J Trauma Resusc Emerg Med 23:51

21. Shi D, Walline JH, Yu X, Xu J, Song PP, Zhu H (2018) Evaluating and assessing the prevalence of bedside ultrasound in emergency departments in China. J Thorac Dis 10(5):2685-2690

22. Ahn C, Kim C, Kang BS, Choi HJ, Cho JH (2015) Variation of availability and frequency of emergency physician-performed ultrasonography between adult and pediatric patients in the academic emergency department in Korea. Clin Exp Emerg Med 2(1):16-23

23. Henwood PC, Beversluis D, Genthon AA et al (2014) Characterizing the limited use of point-of-care ultrasound in Colombian emergency medicine residencies. Int J Emerg Med 7(1):7

24. American College of Emergency Physicians (2017) Ultrasound guidelines: emergency, point-of-care and clinical ultrasound guidelines in medicine. Ann Emerg Med 69(5):e27-e54

25. Moore CL, Molina AA, Lin H (2006) Ultrasonography in community emergency departments in the United States: access to ultrasonography performed by consultants and status of emergency physicianperformed ultrasonography. Ann Emerg Med 47(2):147-153

26. Talley BE, Ginde AA, Raja AS, Sullivan AF, Espinola JA, Camargo CA Jr (2011) Variable access to immediate bedside ultrasound in the emergency department. West J Emerg Med 12(1):96-99

27. Herbst MK, Camargo CA Jr, Perez A, Moore CL (2015) Use of point-ofcare ultrasound in Connecticut emergency departments. J Emerg Med 48(2):191-196.e2

28. Sanders JL, Noble VE, Raja AS, Sullivan AF, Camargo CA Jr (2015) Access to and use of point-of-care ultrasound in the emergency department. West J Emerg Med 16(5):747-752

29. Amini R, Wyman MT, Hernandez NC, Guisto JA, Adhikari S (2017) Use of emergency ultrasound in Arizona community emergency departments. J Ultrasound Med 36(5):913-921

30. Mengarelli M, Nepusz A, Kondrashova T (2018) A comparison of pointof-care ultrasonography use in rural versus urban emergency departments throughout Missouri. Mo Med 115(1):56-60

31. Bratland SZ (1985) Ultrasonic diagnosis in general practice. An evaluation study. Tidsskr Nor Laegeforen 105(28):1939-1940

32. Gillespie ND, Pringle S (1998) A pilot study of the role of echocardiography in primary care. Br J Gen Pract 48(429):1182

33. Mjølstad OC, Snare SR, Folkvord L, Helland F, Grimsmo A, Torp H, Haraldseth $\mathrm{O}$, Haugen BO (2012) Assessment of left ventricular function by GPs using pocket-sized ultrasound. Fam Pract 29(5):534-540

34. Evangelista L, Juncadella E, Copetti S, Pareja A, Torrabadella J, Evangelista A (2013) Diagnostic usefulness of pocket echography performed in hypertensive patients by a general practitioner. Med Clin 141(1):1-7

35. Evangelista A, Galuppo V, Méndez J et al (2016) Hand-held cardiac ultrasound screening performed by family doctors with remote expert support interpretation. Heart 102(5):376-382

36. Moore CL, Rose GA, Tayal VS, Sullivan DM, Arrowood JA, Kline JA (2002) Determination of left ventricular function by emergency physician echocardiography of hypotensive patients. Acad Emerg Med 9(3):186-193

37. Randazzo MR, Snoey ER, Levitt MA, Binder K (2003) Accuracy of emergency physician assessment of left ventricular ejection fraction and central venous pressure using echocardiography. Acad Emerg Med 10(9):973-977

38. Secko MA, Lazar JM, Salciccioli LA, Stone MB (2011) Can junior emergency physicians use E-point septal separation to accurately estimate left ventricular function in acutely dyspneic patients? Acad Emerg Med 18(11):1223-1226

39. Bustam A, Noor Azhar M, Singh Veriah R, Arumugam K, Loch A (2014) Performance of emergency physicians in point-of-care echocardiography following limited training. Emerg Med J 31(5):369-373 
40. McKaigney CJ, Krantz MJ, La Rocque CL, Hurst ND, Buchanan MS, Kendall JL (2014) E-point septal separation: a bedside tool for emergency physician assessment of left ventricular ejection fraction. Am J Emerg Med 32(6):493-497

41. Unlüer EE, Karagöz A, Akoğlu H, Bayata S (2014) Visual estimation of bedside echocardiographic ejection fraction by emergency physicians. West J Emerg Med 15(2):221-226

42. Shah SP, Shah SP, Fils-Aime R, Desir W, Joasil J, Venesy DM, Muruganandan KM (2016) Focused cardiopulmonary ultrasound for assessment of dyspnea in a resource-limited setting. Crit Ultrasound J 8(1):7

43. Farsi D, Hajsadeghi S, Hajighanbari MJ, Mofidi M, Hafezimoghadam P, Rezai M, Mahshidfar B, Abiri S, Abbasi S (2017) Focused cardiac ultrasound (FOCUS) by emergency medicine residents in patients with suspected cardiovascular diseases. J Ultrasound 20(2):133-138

44. Dehbozorgi A, Eslami Nejad S, Mousavi-Roknabadi RS, Sharifi M, Tafakori A, Jalli R (2019) Lung and cardiac ultrasound (LuCUS) protocol in diagnosing acute heart failure in patients with acute dyspnea. Am J Emerg Med. https://doi.org/10.1016/j.ajem.2019.02.040

45. Dinh VA, Ko HS, Rao R, Bansal RC, Smith DD, Kim TE, Nguyen HB (2012) Measuring cardiac index with a focused cardiac ultrasound examination in the ED. Am J Emerg Med 30(9):1845-1851

46. Betcher J, Majkrzak A, Cranford J, Kessler R, Theyyunni N, Huang R (2018) Feasibility study of advanced focused cardiac measurements within the emergency department. Crit Ultrasound J 10(1):10

47. Unlüer EE, Bayata S, Postaci N, Yeşil M, Yavaşi Ö, Kara PH, Vandenberk N, Akay S (2012) Limited bedside echocardiography by emergency physicians for diagnosis of diastolic heart failure. Emerg Med J 29(4):280-283

48. Ehrman RR, Russell FM, Ansari AH, Margeta B, Clary JM, Christian E, Cosby KS, Bailitz J (2015) Can emergency physicians diagnose and correctly classify diastolic dysfunction using bedside echocardiography? Am J Emerg Med 33(9):1178-1183

49. Del Rios M, Colla J, Kotini-Shah P, Briller J, Gerber B, Prendergast H (2018) Emergency physician use of tissue Doppler bedside echocardiography in detecting diastolic dysfunction: an exploratory study. Crit Ultrasound J 10(1):4

50. Nazerian P, Vanni S, Zanobetti M, Polidori G, Pepe G, Federico R, Cangioli E, Grifoni S (2010) Diagnostic accuracy of emergency Doppler echocardiography for identification of acute left ventricular heart failure in patients with acute dyspnea: comparison with Boston criteria and $\mathrm{N}$-terminal prohormone brain natriuretic peptide. Acad Emerg Med $17(1): 18-26$

51. Saul T, Avitabile NC, Berkowitz R, Siadecki SD, Rose G, Toomarian M, Kaban NL, Governatori N, Suprun M (2016) The inter-rater reliability of echocardiographic diastolic function evaluation among emergency physician sonographers. J Emerg Med 51(4):411-417

52. Croft PE, Strout TD, Kring RM, Director L, Vasaiwala SC, Mackenzie DC (2019) WAMAMI: emergency physicians can accurately identify wall motion abnormalities in acute myocardial infarction. Am J Emerg Med. https://doi.org/10.1016/j.ajem.2019.03.037

53. Reardon L, Scheels WJ, Singer AJ, Reardon RF (2018) Feasibility and accuracy of speckle tracking echocardiography in emergency department patients. Am J Emerg Med 36(12):2254-2259

54. Mandavia DP, Hoffner RJ, Mahaney K, Henderson SO (2001) Bedside echocardiography by emergency physicians. Ann Emerg Med 38(4):377-382

55. Martindale JL, Wakai A, Collins SP, Levy PD, Diercks D, Hiestand BC, Fermann GJ, deSouza I, Sinert R (2016) Diagnosing acute heart failure in the emergency department: a systematic review and meta-analysis. Acad Emerg Med 23(3):223-242

56. McGivery K, Atkinson P, Lewis D, Taylor L, Harris T, Gadd K, Fraser J, Stoica $\mathrm{G}$ (2018) Emergency department ultrasound for the detection of B-lines in the early diagnosis of acute decompensated heart failure: a systematic review and meta-analysis. CJEM 20(3):343-352

57. Lian R, Zhang GC, Yan ST, Sun LC, Zhang SQ, Zhang GQ (2018) Role of ultrasound lung comets in the diagnosis of acute heart failure in emergency department: a systematic review and meta-analysis. Biomed Environ Sci 31(8):596-607

58. Maw AM, Hassanin A, Ho PM et al (2019) Diagnostic accuracy of point-of-care lung ultrasonography and chest radiography in adults with symptoms suggestive of acute decompensated heart failure: a systematic review and meta-analysis. JAMA Netw Open 2(3):e190703
59. Staub LJ, Mazzali Biscaro RR, Kaszubowski E, Maurici R (2019) Lung ultrasound for the emergency diagnosis of pneumonia, acute heart failure, and exacerbations of chronic obstructive pulmonary disease/asthma in adults: a systematic review and meta-analysis. J Emerg Med 56(1):53-69

60. Pivetta E, Goffi A, Nazerian P et al (2019) Lung ultrasound integrated with clinical assessment for the diagnosis of acute decompensated heart failure in the emergency department: a randomized controlled trial. Eur J Heart Fail. https://doi.org/10.1002/ejhf.1379

61. Baker K, Mitchell G, Stieler G (2013) Limited lung ultrasound protocol in elderly patients with breathlessness; agreement between bedside interpretation and stored images as acquired by experienced and inexperienced sonologists. Australas J Ultrasound Med 16(2):86-92

62. Orso D, Guglielmo N, Copetti R (2018) Lung ultrasound in diagnosing pneumonia in the emergency department: a systematic review and meta-analysis. Eur J Emerg Med 25(5):312-321

63. Ye X, Xiao H, Chen B, Zhang S (2015) Accuracy of lung ultrasonography versus chest radiography for the diagnosis of adult communityacquired pneumonia: review of the literature and meta-analysis. PLoS ONE 10(6):e0130066

64. Amatya Y, Rupp J, Russell FM, Saunders J, Bales B, House DR (2018) Diagnostic use of lung ultrasound compared to chest radiograph for suspected pneumonia in a resource-limited setting. Int J Emerg Med 11(1):8

65. Copetti R, Cattarossi L (2008) Ultrasound diagnosis of pneumonia in children. Radiol Med 113(2):190-198

66. Shah VP, Tunik MG, Tsung JW (2013) Prospective evaluation of point-ofcare ultrasonography for the diagnosis of pneumonia in children and young adults. JAMA Pediatr 167(2):119-125

67. Yilmaz HL, Özkaya AK, Sarı Gökay S, Tolu Kendir Ö, Şenol H (2017) Point-of-care lung ultrasound in children with community acquired pneumonia. Am J Emerg Med 35(7):964-969

68. Jones BP, Tay ET, Elikashvili I, Sanders JE, Paul AZ, Nelson BP, Spina LA, Tsung JW (2016) Feasibility and safety of substituting lung ultrasonography for chest radiography when diagnosing pneumonia in children: a randomized controlled trial. Chest 150(1):131-138

69. Harel-Sterling M, Diallo M, Santhirakumaran S, Maxim T, Tessaro M (2019) Emergency department resource use in pediatric pneumonia: point-of-care lung ultrasonography versus chest radiography. J Ultrasound Med 38(2):407-414

70. Ebrahimi A, Yousefifard M, Mohammad Kazemi H, Rasouli HR, Asady H, Moghadas Jafari A, Hosseini M (2014) Diagnostic accuracy of chest ultrasonography versus chest radiography for identification of pneumothorax: a systematic review and meta-analysis. Tanaffos 13(4):29-40

71. Staub LJ, Biscaro RRM, Kaszubowski E, Maurici R (2018) Chest ultrasonography for the emergency diagnosis of traumatic pneumothorax and haemothorax: a systematic review and meta-analysis. Injury 49(3):457-466

72. Riccardi A, Spinola MB, Ghiglione V, Licenziato M, Lerza R (2019) PoCUS evaluating blunt thoracic trauma: a retrospective analysis of 18 months of emergency department activity. Eur J Orthop Surg Traumatol 29(1):31-35

73. Lalande É, Guimont C, Émond M, Parent MC, Topping C, Kuimi BLB, Boucher V, Le Sage N (2017) Feasibility of emergency department point-of-care ultrasound for rib fracture diagnosis in minor thoracic injury. CJEM 19(3):213-219

74. Pishbin E, Ahmadi K, Foogardi M, Salehi M, Seilanian Toosi F, RahimiMovaghar V (2017) Comparison of ultrasonography and radiography in diagnosis of rib fractures. Chin J Traumatol 20(4):226-228

75. Koh Y, Chua MT, Ho WH, Lee C, Chan GWH, Sen Kuan W (2018) Assessment of dyspneic patients in the emergency department using pointof-care lung and cardiac ultrasonography-a prospective observational study. J Thorac Dis 10(11):6221-6229

76. Bekgoz B, Kilicaslan I, Bildik F, Keles A, Demircan A, Hakoglu O, Coskun G, Demir HA (2019) BLUE protocol ultrasonography in emergency department patients presenting with acute dyspnea. Am J Emerg Med. https ://doi.org/10.1016/j.ajem.2019.02.028

77. Volpicelli G, Cardinale L, Berchialla P, Mussa A, Bar F, Frascisco MF (2012) A comparison of different diagnostic tests in the bedside evaluation of pleuritic pain in the ED. Am J Emerg Med 30(2):317-324

78. Goffi A, Pivetta E, Lupia E, Porrino G, Civita M, Laurita E, Griot G, Casoli G, Cibinel G (2013) Has lung ultrasound an impact on the management of 
patients with acute dyspnea in the emergency department? Crit Care 17(4):R180

79. Laursen CB, Sloth E, Lambrechtsen J, Lassen AT, Madsen PH, Henriksen DP, Davidsen JR, Rasmussen F (2013) Focused sonography of the heart, lungs, and deep veins identifies missed life-threatening conditions in admitted patients with acute respiratory symptoms. Chest 144(6):1868-1875

80. Laursen CB, Sloth E, Lassen AT, Christensen RD, Lambrechtsen J, Madsen PH, Henriksen DP, Davidsen JR, Rasmussen F (2014) Point-of-care ultrasonography in patients admitted with respiratory symptoms: a singleblind, randomised controlled trial. Lancet Respir Med 2(8):638-646

81. Zanobetti M, Scorpiniti M, Gigli C et al (2017) Point-of-care ultrasonography for evaluation of acute dyspnea in the ED. Chest 151(6):1295-1301

82. Seyedhosseini J, Bashizadeh-Fakhar G, Farzaneh S, Momeni M, Karimialavijeh E (2017) The impact of the BLUE protocol ultrasonography on the time taken to treat acute respiratory distress in the ED. Am J Emerg Med 35(12):1815-1818

83. Buhumaid RE, St-Cyr Bourque J, Shokoohi H, Ma IWY, Longacre M, Liteplo AS (2019) Integrating point-of-care ultrasound in the ED evaluation of patients presenting with chest pain and shortness of breath. Am J Emerg Med 37(2):298-303

84. Zanobetti M, Poggioni C, Pini R (2011) Can chest ultrasonography replace standard chest radiography for evaluation of acute dyspnea in the ED? Chest 139(5):1140-1147

85. Sforza A, Mancusi C, Carlino MV, Buonauro A, Barozzi M, Romano G, Serra S, de Simone G (2017) Diagnostic performance of multi-organ ultrasound with pocket-sized device in the management of acute dyspnea. Cardiovasc Ultrasound 15(1):16

86. Carlino MV, Paladino F, Sforza A, Serra C, Liccardi F, de Simone G, Mancusi C (2018) Assessment of left atrial size in addition to focused cardiopulmonary ultrasound improves diagnostic accuracy of acute heart failure in the emergency department. Echocardiography 35(6):785-791

87. Papanagnou D, Secko M, Gullett J, Stone M, Zehtabchi S (2017) Clinician-performed bedside ultrasound in improving diagnostic accuracy in patients presenting to the ED with acute dyspnea. West J Emerg Med 18(3):382-389

88. Blois B (2012) Office-based ultrasound screening for abdominal aortic aneurysm. Can Fam Physician 58(3):e172-e178

89. Bailey RP, Ault M, Greengold NL, Rosendahl T, Cossman D (2001) Ultrasonography performed by primary care residents for abdominal aortic aneurysm screening. J Gen Intern Med 16(12):845-849

90. Bravo-Merino L, González-Lozano N, Maroto-Salmón R, Meijide-Santos G, Suárez-Gil P, Fañanás-Mastral A (2019) Validity of the abdominal ecography in primary care for detection of aorta abdominal aneurism in male between 65 and 75 years. Aten Primaria 51(1):11-17

91. Sisó-Almirall A, Kostov B, Navarro González M et al (2017) Abdominal aortic aneurysm screening program using hand-held ultrasound in primary healthcare. PLoS ONE 12(4): 0176877

92. Hoffmann B, Um P, Bessman ES, Ding R, Kelen GD, McCarthy ML (2009) Routine screening for asymptomatic abdominal aortic aneurysm in high-risk patients is not recommended in emergency departments that are frequently crowded. Acad Emerg Med 16(11):1242-1250

93. Lindgaard K, Riisgaard L (2017) Validation of ultrasound examinations performed by general practitioners. Scand J Prim Health Care 35(3):256-261

94. Rubano E, Mehta N, Caputo W, Paladino L, Sinert R (2013) Systematic review: emergency department bedside ultrasonography for diagnosing suspected abdominal aortic aneurysm. Acad Emerg Med 20(2):128-138

95. Okahara A, Sadamatsu K, Matsuura T, Koga Y, Mine D, Yoshida K (2016) Coronary artery disease screening with carotid ultrasound examination by a primary care physician. Cardiol Res Pract 7(1):9-16

96. Mumoli N, Vitale J, Giorgi-Pierfranceschi M et al (2017) General practitioner-performed compression ultrasonography for diagnosis of deep vein thrombosis of the leg: a multicenter, prospective cohort study. Ann Fam Med 15(6):535-539

97. Pomero F, Dentali F, Borretta V, Bonzini M, Melchio R, Douketis JD, Fenoglio LM (2013) Accuracy of emergency physician-performed ultrasonography in the diagnosis of deep-vein thrombosis: a systematic review and meta-analysis. Thromb Haemost 109(1):137-145
98. Lee JH, Lee SH, Yun SJ (2019) Comparison of 2-point and 3-point point-of-care ultrasound techniques for deep vein thrombosis at the emergency department: a meta-analysis. Medicine 98(22):e15791

99. Torres-Macho J, Antón-Santos JM, García-Gutierrez I et al (2012) Initial accuracy of bedside ultrasound performed by emergency physicians for multiple indications after a short training period. Am J Emerg Med 30(9):1943-1949

100. Crowhurst TD, Dunn RJ (2013) Sensitivity and specificity of three-point compression ultrasonography performed by emergency physicians for proximal lower extremity deep venous thrombosis. Emerg Med Australas 25(6):588-596

101. Nygren D, Hård Af Segerstad C, Ellehuus Hilmersson C, Elf J, Ulf E, Lundager Forberg J (2018) Good outcomes when emergency physicians diagnosed deep vein thrombosis. Lakartidningen 115(3):92-95

102. Seyedhosseini J, Fadavi A, Vahidi E, Saeedi M, Momeni M (2018) Impact of point-of-care ultrasound on disposition time of patients presenting with lower extremity deep vein thrombosis, done by emergency physicians. Turk J Emerg Med 18(1):20-24

103. Costantino TG, Parikh AK, Satz WA, Fojtik JP (2005) Ultrasonographyguided peripheral intravenous access versus traditional approaches in patients with difficult intravenous access. Ann Emerg Med 46(5):456-461

104. Dargin JM, Rebholz CM, Lowenstein RA, Mitchell PM, Feldman JA (2010) Ultrasonography-guided peripheral intravenous catheter survival in ED patients with difficult access. Am J Emerg Med 28(1):1-7

105. Vinograd AM, Zorc JJ, Dean AJ, Abbadessa MKF, Chen AE (2018) First-attempt success, longevity, and complication rates of ultrasoundguided peripheral intravenous catheters in children. Pediatr Emerg Care 34(6):376-380

106. Stein J, George B, River G, Hebig A, McDermott D (2009) Ultrasonographically guided peripheral intravenous cannulation in emergency department patients with difficult intravenous access: a randomized trial. Ann Emerg Med 54(1):33-40

107. Oakley E, Wong A-M (2010) Ultrasound-assisted peripheral vascular access in a paediatric ED. Emerg Med Australas 22(2):166-170

108. Otani T, Morikawa Y, Hayakawa I et al (2018) Ultrasound-guided peripheral intravenous access placement for children in the emergency department. Eur J Pediatr 177(10):1443-1449

109. Rupp JD, Ferre RM, Boyd JS, Dearing E, McNaughton CD, Liu D, Jarrell KL, McWade CM, Self WH (2016) Extravasation risk using ultrasound-guided peripheral intravenous catheters for computed tomography contrast administration. Acad Emerg Med 23(8):918-921

110. Keyes LE, Frazee BW, Snoey ER, Simon BC, Christy D (1999) Ultrasoundguided brachial and basilic vein cannulation in emergency department patients with difficult intravenous access. Ann Emerg Med 34(6):711-714

111. Schnadower D, Lin S, Perera P, Smerling A, Dayan P (2007) A pilot study of ultrasound analysis before pediatric peripheral vein cannulation attempt. Acad Emerg Med 14(5):483-485

112. Zitek T, Busby E, Hudson H, McCourt JD, Baydoun J, Slattery DE (2018) Ultrasound-guided placement of single-lumen peripheral intravenous catheters in the internal jugular vein. West J Emerg Med 19(5):808-812

113. Wong C, Teitge B, Ross M, Young P, Robertson HL, Lang E (2018) The accuracy and prognostic value of point-of-care ultrasound for nephrolithiasis in the emergency department: a systematic review and meta-analysis. Acad Emerg Med 25(6):684-698

114. Javaudin F, Mounier F, Pes P, Arnaudet I, Vignaud F, Frampas E, Le Conte P. Winfocus-France study group (2017) Evaluation of a short formation on the performance of point-of-care renal ultrasound performed by physicians without previous ultrasound skills: prospective observational study. Crit Ultrasound J 9(1):23

115. Guedj R, Escoda S, Blakime P, Patteau G, Brunelle F, Cheron G (2015) The accuracy of renal point of care ultrasound to detect hydronephrosis in children with a urinary tract infection. Eur J Emerg Med 22(2):135-138

116. Smith-Bindman R, Aubin C, Bailitz J et al (2014) Ultrasonography versus computed tomography for suspected nephrolithiasis. N Engl J Med 371(12):1100-1110

117. Park YH, Jung RB, Lee YG, Hong CK, Ahn J-H, Shin TY, Kim YS, Ha YR (2016) Does the use of bedside ultrasonography reduce emergency department length of stay for patients with renal colic?: a pilot study. Clin Exp Emerg Med 3(4):197-203 
118. Blaivas M, Sierzenski P, Lambert M (2001) Emergency evaluation of patients presenting with acute scrotum using bedside ultrasonography. Acad Emerg Med 8(1):90-93

119. Bratland SZ, Nordshus T (1985) Ultrasonography of the gallbladder in general practice. Tidsskr Nor Laegeforen 105(28):1946-1948

120. Eggebø TM, Sørvang S, Dalaker K (1990) Ultrasonic diagnosis of the upper abdomen performed in general practice. Tidsskr Nor Laegeforen 110(9):1096-1098

121. Esquerrà M, Roura Poch P, Masat Ticó T, Canal V, Maideu Mir J, Cruxent R (2012) Abdominal ultrasound: a diagnostic tool within the reach of general practitioners. Aten Primaria 44(10):576-583

122. Schlager D, Lazzareschi G, Whitten D, Sanders AB (1994) A prospective study of ultrasonography in the ED by emergency physicians. Am J Emerg Med 12(2):185-189

123. Blaivas M, Harwood RA, Lambert MJ (1999) Decreasing length of stay with emergency ultrasound examination of the gallbladder. Acad Emerg Med 6(10):1020-1023

124. Ross M, Brown M, McLaughlin K, Atkinson P, Thompson J, Powelson S, Clark S, Lang E (2011) Emergency physician-performed ultrasound to diagnose cholelithiasis: a systematic review. Acad Emerg Med 18(3):227-235

125. Scruggs W, Fox JC, Potts B, Zlidenny A, McDonough J, Anderson CL, Larson J, Barajas G, Langdorf MI (2008) Accuracy of ED bedside ultrasound for identification of gallstones: retrospective analysis of 575 studies. West J Emerg Med 9(1):1-5

126. Hilsden R, Leeper R, Koichopolos J, Vandelinde JD, Parry N, Thompson D, Myslik F (2018) Point-of-care biliary ultrasound in the emergency department (BUSED): implications for surgical referral and emergency department wait times. Trauma Surg Acute Care Open 3(1):e000164

127. Rosen CL, Brown DF, Chang Y, Moore C, Averill NJ, Arkoff LJ, McCabe CJ, Wolfe RE (2001) Ultrasonography by emergency physicians in patients with suspected cholecystitis. Am J Emerg Med 19(1):32-36

128. Summers SM, Scruggs W, Menchine MD, Lahham S, Anderson C, Amr O, Lotfipour S, Cusick SS, Fox JC (2010) A prospective evaluation of emergency department bedside ultrasonography for the detection of acute cholecystitis. Ann Emerg Med 56(2):114-122

129. Shekarchi B, Hejripour Rafsanjani SZ, Shekar Riz Fomani N, Chahardoli M (2018) Emergency department bedside ultrasonography for diagnosis of acute cholecystitis; a diagnostic accuracy study. Emergency 6(1):e11

130. Tootian Tourghabe J, Arabikhan HR, Alamdaran A, Zamani Moghadam $H(2018)$ Emergency medicine resident versus radiologist in detecting the ultrasonographic signs of acute cholecystitis; a diagnostic accuracy study. Emergency 6(1):e19

131. Bektas F, Eken C, Soyuncu S, Kusoglu L, Cete Y (2009) Contribution of goal-directed ultrasonography to clinical decision-making for emergency physicians. Emerg Med J 26(3):169-172

132. Adhikari S, Morrison D, Lyon M, Zeger W, Krueger A (2014) Utility of point-of-care biliary ultrasound in the evaluation of emergency patients with isolated acute non-traumatic epigastric pain. Intern Emerg Med 9(5):583-587

133. Lahham S, Becker BA, Gari A, Bunch S, Alvarado M, Anderson CL, Viquez E, Spann SC, Fox JC (2018) Utility of common bile duct measurement in ED point of care ultrasound: a prospective study. Am J Emerg Med 36(6):962-966

134. Benabbas R, Hanna M, Shah J, Sinert R (2017) Diagnostic accuracy of history, physical examination, laboratory tests, and point-of-care ultrasound for pediatric acute appendicitis in the emergency department: a systematic review and meta-analysis. Acad Emerg Med 24(5):523-551

135. Nicole M, Desjardins MP, Gravel J (2018) Bedside sonography performed by emergency physicians to detect appendicitis in children. Acad Emerg Med. https://doi.org/10.1111/acem.13445

136. Lee SH, Yun SJ (2019) Diagnostic performance of emergency physicianperformed point-of-care ultrasonography for acute appendicitis: a meta-analysis. Am J Emerg Med 37(4):696-705

137. Fields JM, Davis J, Alsup C, Bates A, Au A, Adhikari S, Farrell I (2017) Accuracy of point-of-care ultrasonography for diagnosing acute appendicitis: a systematic review and meta-analysis. Acad Emerg Med 24(9):1124-1136

138. Shahbazipar M, Seyedhosseini J, Vahidi E, Sheikh Motahar Vahedi H, Jahanshir A (2018) Accuracy of ultrasound exam performed by emergency medicine versus radiology residents in the diagnosis of acute appendicitis. Eur J Emerg Med. https://doi.org/10.1097/MEJ.00000 00000000547

139. Sharif S, Skitch S, Vlahaki D, Healey A (2018) Point-of-care ultrasound to diagnose appendicitis in a Canadian emergency department. CJEM 20(5):732-735

140. Corson-Knowles D, Russell FM (2018) Clinical ultrasound is safe and highly specific for acute appendicitis in moderate to high pre-test probability patients. West J Emerg Med 19(3):460-464

141. Riera A, Hsiao AL, Langhan ML, Goodman TR, Chen L (2012) Diagnosis of intussusception by physician novice sonographers in the emergency department. Ann Emerg Med 60(3):264-268

142. Lam SHF, Wise A, Yenter C (2014) Emergency bedside ultrasound for the diagnosis of pediatric intussusception: a retrospective review. World J Emerg Med 5(4):255-258

143. Chang Y-J, Hsia S-H, Chao H-C (2013) Emergency medicine physicians performed ultrasound for pediatric intussusceptions. Biomed J 36(4):175-178

144. Kim JH, Lee J-Y, Kwon JH, Cho H-R, Lee JS, Ryu J-M (2017) Point-of-care ultrasound could streamline the emergency department workflow of clinically nonspecific intussusception. Pediatr Emerg Care. https://doi. org/10.1097/PEC.0000000000001283

145. Becker BA, Lahham S, Gonzales MA, Nomura JT, Bui MK, Truong TA, Stahlman BA, Fox JC, Kehrl T (2019) A prospective, multicenter evaluation of point-of-care ultrasound for small-bowel obstruction in the emergency department. Acad Emerg Med. https://doi.org/10.1111/ acem. 13713

146. Unlüer EE, Yavaşi O, Eroğlu O, Yilmaz C, Akarca FK (2010) Ultrasonography by emergency medicine and radiology residents for the diagnosis of small bowel obstruction. Eur J Emerg Med 17(5):260-264

147. Jang TB, Schindler D, Kaji AH (2011) Bedside ultrasonography for the detection of small bowel obstruction in the emergency department. Emerg Med J 28(8):676-678

148. Frasure SE, Hildreth AF, Seethala R, Kimberly HH (2018) Accuracy of abdominal ultrasound for the diagnosis of small bowel obstruction in the emergency department. World J Emerg Med 9(4):267-271

149. Doniger SJ, Dessie A, Latronica C (2018) Measuring the transrectal diameter on point-of-care ultrasound to diagnose constipation in children. Pediatr Emerg Care 34(3):154-159

150. Hasani SA, Fathi M, Daadpey M, Zare MA, Tavakoli N, Abbasi S (2015) Accuracy of bedside emergency physician performed ultrasound in diagnosing different causes of acute abdominal pain: a prospective study. Clin Imaging 39(3):476-479

151. Bourcier J-E, Gallard E, Redonnet J-P, Majourau M, Deshaie D, Bourgeois J-M, Garnier D, Geeraerts T (2018) Diagnostic performance of abdominal point of care ultrasound performed by an emergency physician in acute right iliac fossa pain. Crit Ultrasound J 10(1):31

152. Johansen I, Grimsmo A, Nakling J (2002) Ultrasonography in primary health care-experiences within obstetrics 1983-99. Tidsskr Nor Laegeforen 122(20):1995-1998

153. Bratland SZ, Eik-Nes SH (1985) Ultrasonic diagnosis of pregnant women in general practice. Tidsskr Nor Laegeforen 105(28):1940-1946

154. Eggebø TM, Dalaker K (1989) Ultrasonic diagnosis of pregnant women performed in general practice. Tidsskr Nor Laegeforen 109(29):2979-2981

155. Ornstein SM, Smith MA, Peggs J, Garr D, Gonzales J (1990) Obstetric ultrasound by family physicians. Adequacy as assessed by pregnancy outcome. J Fam Pract 30(4):403-408

156. Rodney WM, Prislin MD, Orientale E, McConnell M, Hahn RG (1990) Family practice obstetric ultrasound in an urban community health center. Birth outcomes and examination accuracy of the initial 227 cases. J Fam Pract 30(2):163-168

157. Brunader R (1996) Accuracy of prenatal sonography performed by family practice residents. Fam Med 28(6):407-410

158. Keith R, Frisch L (2001) Fetal biometry: a comparison of family physicians and radiologists. Fam Med 33(2):111-114

159. Bailey C, Carnell J, Vahidnia F, Shah S, Stone M, Adams M, Nagdev A (2012) Accuracy of emergency physicians using ultrasound measurement of crown-rump length to estimate gestational age in pregnant females. Am J Emerg Med 30(8):1627-1629 
160. Saul T, Lewiss RE, Rivera MDR (2012) Accuracy of emergency physician performed bedside ultrasound in determining gestational age in first trimester pregnancy. Crit Ultrasound J 4(1):22

161. Shah S, Teismann N, Zaia B, Vahidnia F, River G, Price D, Nagdev A (2010) Accuracy of emergency physicians using ultrasound to determine gestational age in pregnant women. Am J Emerg Med 28(7):834-838

162. Stein JC, Wang R, Adler N, Boscardin J, Jacoby VL, Won G, Goldstein R, Kohn MA (2010) Emergency physician ultrasonography for evaluating patients at risk for ectopic pregnancy: a meta-analysis. Ann Emerg Med 56(6):674-683

163. Beals T, Naraghi L, Grossestreuer A, Schafer J, Balk D, Hoffmann B (2019) Point of care ultrasound is associated with decreased ED length of stay for symptomatic early pregnancy. Am J Emerg Med 37(6):1165-1168

164. Strommen J, Masullo L, Crowell T, Moffett P (2017) First-trimester vaginal bleeding: patient expectations when presenting to the emergency department. Mil Med 182(11):e1824-e1826

165. Everett CB, Preece E (1996) Women with bleeding in the first 20 weeks of pregnancy: value of general practice ultrasound in detecting fetal heart movement. Br J Gen Pract 46(402):7-9

166. Varner C, Balaban D, McLeod S, Carver S, Borgundvaag B (2016) Fetal outcomes following emergency department point-of-care ultrasound for vaginal bleeding in early pregnancy. Can Fam Physician 62(7):572-578

167. Shah S, Adedipe A, Ruffatto B, Backlund BH, Sajed D, Rood K, Fernandez R (2014) BE-SAFE: bedside sonography for assessment of the fetus in emergencies: educational intervention for late-pregnancy obstetric ultrasound. West J Emerg Med 15(6):636-640

168. Gottlieb M, Holladay D, Peksa GD (2019) Point-of-care ocular ultrasound for the diagnosis of retinal detachment: a systematic review and metaanalysis. Acad Emerg Med. https://doi.org/10.1111/acem.13682

169. Jacobsen B, Lahham S, Lahham S, Patel A, Spann S, Fox JC (2016) Retrospective review of ocular point-of-care ultrasound for detection of retinal detachment. West J Emerg Med 17(2):196-200

170. Lahham S, Shniter I, Thompson M, Le D, Chadha T, Mailhot T, Kang TL, Chiem A, Tseeng S, Fox JC (2019) Point-of-care ultrasonography in the diagnosis of retinal detachment, vitreous hemorrhage, and vitreous detachment in the emergency department. JAMA Netw Open 2(4):e192162

171. Ojaghihaghighi S, Lombardi KM, Davis S, Vahdati SS, Sorkhabi R, Pourmand A (2019) Diagnosis of traumatic eye injuries with point-of-care ocular ultrasonography in the emergency department. Ann Emerg Med. https://doi.org/10.1016/j.annemergmed.2019.02.001

172. Ojaghi Haghighi SH, Morteza Begi HR, Sorkhabi R, Tarzamani MK, Kamali Zonouz G, Mikaeilpour A, Rahmani F (2014) Diagnostic accuracy of ultrasound in detection of traumatic lens dislocation. Emergency 2(3):121-124

173. Barbic D, Chenkin J, Cho DD, Jelic T, Scheuermeyer FX (2017) In patients presenting to the emergency department with skin and soft tissue infections what is the diagnostic accuracy of point-of-care ultrasonography for the diagnosis of abscess compared to the current standard of care? A systematic review and meta-analysis. BMJ Open 7(1):e013688

174. Subramaniam S, Bober J, Chao J, Zehtabchi S (2016) Point-of-care ultrasound for diagnosis of abscess in skin and soft tissue infections. Acad Emerg Med 23(11):1298-1306

175. Gaspari R, Dayno M, Briones J, Blehar D (2012) Comparison of computerized tomography and ultrasound for diagnosing soft tissue abscesses. Crit Ultrasound J 4(1):5

176. Greenlund LS, Merry SP, Thacher TD, Ward WJ (2017) Primary care management of skin abscesses guided by ultrasound. Am J Med 130(5):e191-e193

177. Mower WR, Crisp JG, Krishnadasan A, Moran GJ, Abrahamian FM, Lovecchio F, Karras DJ, Steele MT, Rothman RE, Talan DA (2019) Effect of initial bedside ultrasonography on emergency department skin and soft tissue infection management. Ann Emerg Med. https://doi.org/10.1016/j. annemergmed.2019.02.002

178. Lam SHF, Sivitz A, Alade K et al (2018) Comparison of ultrasound guidance vs. clinical assessment alone for management of pediatric skin and soft tissue infections. J Emerg Med 55(5):693-701

179. Gaspari RJ, Sanseverino A (2018) Ultrasound-guided drainage for pediatric soft tissue abscesses decreases clinical failure rates compared to drainage without ultrasound: a retrospective study. J Ultrasound Med 37(1):131-136

180. Gaspari RJ, Sanseverino A, Gleeson T (2019) Abscess incision and drainage with or without ultrasonography: a randomized controlled trial. Ann Emerg Med 73(1):1-7

181. Lin MJ, Neuman M, Rempell R, Monuteaux M, Levy J (2018) Point-ofcare ultrasound is associated with decreased length of stay in children presenting to the emergency department with soft tissue infection. J Emerg Med 54(1):96-101

182. Costantino TG, Satz WA, Dehnkamp W, Goett H (2012) Randomized trial comparing intraoral ultrasound to landmark-based needle aspiration in patients with suspected peritonsillar abscess. Acad Emerg Med 19(6):626-631

183. Adhikari S, Blaivas M, Lander L (2011) Comparison of bedside ultrasound and panorex radiography in the diagnosis of a dental abscess in the ED. Am J Emerg Med 29(7):790-795

184. Levine MC, Arroyo A, Likourezos A, Homel P, Dickman E (2018) The use of point of care ultrasound in the evaluation of pediatric soft tissue neck masses. Am J Emerg Med. https://doi.org/10.1016/j. ajem.2018.10.048

185. Friedman N, Tseng F, Savic R, Diallo M, Fathi K, Mclean L, Tessaro MO (2019) Reliability of neck mass point-of-care ultrasound by pediatric emergency physicians. J Ultrasound Med. https://doi.org/10.1002/ jum.14993

186. Friedman DI, Forti RJ, Wall SP, Crain EF (2005) The utility of bedside ultrasound and patient perception in detecting soft tissue foreign bodies in children. Pediatr Emerg Care 21(8):487-492

187. Oguz AB, Polat O, Eneyli MG, Gulunay B, Eksioglu M, Gurler S (2017) The efficiency of bedside ultrasonography in patients with wrist injury and comparison with other radiological imaging methods: a prospective study. Am J Emerg Med 35(6):855-859

188. Lee SH, Yun SJ (2018) Point-of-care wrist ultrasonography in trauma patients with ulnar-sided pain and instability. Am J Emerg Med 36(5):859-864

189. Gün C, Unlüer EE, Vandenberk N, Karagöz A, Sentürk GO, Oyar O (2013) Bedside ultrasonography by emergency physicians for anterior talofibular ligament injury. J Emerg Trauma Shock 6(3):195-198

190. Lee SH, Yun SJ (2017) The feasibility of point-of-care ankle ultrasound examination in patients with recurrent ankle sprain and chronic ankle instability: comparison with magnetic resonance imaging. Injury 48(10):2323-2328

191. Wu TS, Roque PJ, Green J, Drachman D, Khor K-N, Rosenberg M, Simpson C (2012) Bedside ultrasound evaluation of tendon injuries. Am J Emerg Med 30(8):1617-1621

192. Mohammadrezaei N, Seyedhosseini J, Vahidi E (2017) Validity of ultrasound in diagnosis of tendon injuries in penetrating extremity trauma. Am J Emerg Med 35(7):945-948

193. Vieira RL, Levy JA (2010) Bedside ultrasonography to identify hip effusions in pediatric patients. Ann Emerg Med 55(3):284-289

194. Cruz Cl, Vieira RL, Mannix RC, Monuteaux MC, Levy JA (2018) Point-ofcare hip ultrasound in a pediatric emergency department. Am J Emerg Med 36(7):1174-1177

195. Adhikari S, Blaivas M (2010) Utility of bedside sonography to distinguish soft tissue abnormalities from joint effusions in the emergency department. J Ultrasound Med 29(4):519-526

196. Gottlieb M, Holladay D, Peksa GD (2019) Point-of-care ultrasound for the diagnosis of shoulder dislocation: a systematic review and metaanalysis. Am J Emerg Med 37(4):757-761

197. Lee SH, Yun SJ (2019) Efficiency of knee ultrasound for diagnosing anterior cruciate ligament and posterior cruciate ligament injuries: a systematic review and meta-analysis. Skel Radiol. https://doi.org/10.1007/ s00256-019-03225-w

198. Weinberg ER, Tunik MG, Tsung JW (2010) Accuracy of clinicianperformed point-of-care ultrasound for the diagnosis of fractures in children and young adults. Injury 41(8):862-868

199. Riera A, Chen L (2012) Ultrasound evaluation of skull fractures in children: a feasibility study. Pediatr Emerg Care 28(5):420-425

200. Parri N, Crosby BJ, Glass C, Mannelli F, Sforzi I, Schiavone R, Ban KM (2013) Ability of emergency ultrasonography to detect pediatric skull fractures: a prospective, observational study. J Emerg Med 44(1):135-141 
201. Rabiner JE, Friedman LM, Khine H, Avner JR, Tsung JW (2013) Accuracy of point-of-care ultrasound for diagnosis of skull fractures in children. Pediatrics 131(6):e1757-e1764

202. Choi JY, Lim YS, Jang JH, Park WB, Hyun SY, Cho JS (2018) Accuracy of bedside ultrasound for the diagnosis of skull fractures in children aged 0 to 4 years. Pediatr Emerg Care. https://doi.org/10.1097/PEC.00000 00000001485

203. Parri N, Crosby BJ, Mills L, Soucy Z, Musolino AM, Da Dalt L, Cirilli A, Grisotto L, Kuppermann N (2018) Point-of-care ultrasound for the diagnosis of skull fractures in children younger than two years of age. J Pediatr 196:230-236.e2

204. Cross KP, Warkentine FH, Kim IK, Gracely E, Paul RI (2010) Bedside ultrasound diagnosis of clavicle fractures in the pediatric emergency department. Acad Emerg Med 17(7):687-693

205. Chien M, Bulloch B, Garcia-Filion P, Youssfi M, Shrader MW, Segal LS (2011) Bedside ultrasound in the diagnosis of pediatric clavicle fractures. Pediatr Emerg Care 27(11):1038-1041

206. Lee SH, Yun SJ (2019) Diagnostic performance of ultrasonography for detection of pediatric elbow fracture: a meta-analysis. Ann Emerg Med. https://doi.org/10.1016/j.annemergmed.2019.03.009

207. Rabiner JE, Khine H, Avner JR, Tsung JW (2015) Ultrasound findings of the elbow posterior fat pad in children with radial head subluxation. Pediatr Emerg Care 31(5):327-330

208. Chartier LB, Bosco L, Lapointe-Shaw L, Chenkin J (2017) Use of pointof-care ultrasound in long bone fractures: a systematic review and meta-analysis. CJEM 19(2):131-142

209. Hedelin H, Tingström C, Hebelka H, Karlsson J (2017) Minimal training sufficient to diagnose pediatric wrist fractures with ultrasound. Crit Ultrasound J 9(1):11

210. Rowlands R, Rippey J, Tie S, Flynn J (2017) Bedside ultrasound vs $X$-ray for the diagnosis of forearm fractures in children. J Emerg Med 52(2):208-215

211. Douma-den Hamer D, Blanker MH, Edens MA, Buijteweg LN, Boomsma MF, van Helden SH, Mauritz G-J (2016) Ultrasound for distal forearm fracture: a systematic review and diagnostic meta-analysis. PLOS ONE 11(5):e0155659

212. Sivrikaya S, Aksay E, Bayram B, Oray NC, Karakasli A, Altintas E (2016) Emergency physicians performed point-of-care-ultrasonography for detecting distal forearm fracture. Turk J Emerg Med 16(3):98-101

213. Tayal VS, Antoniazzi J, Pariyadath M, Norton HJ (2007) Prospective use of ultrasound imaging to detect bony hand injuries in adults. J Ultrasound Med 26(9):1143-1148

214. Neri E, Barbi E, Rabach I, Zanchi C, Norbedo S, Ronfani L, Guastalla V, Ventura A, Guastalla P (2014) Diagnostic accuracy of ultrasonography for hand bony fractures in paediatric patients. Arch Dis Child 99(12):1087-1090
215. Kozaci N, Ay MO, Akcimen M, Sasmaz I, Turhan G, Boz A (2015) The effectiveness of bedside point-of-care ultrasonography in the diagnosis and management of metacarpal fractures. Am J Emerg Med 33(10):1468-1472

216. Aksay E, Yesilaras M, Kılıc TY, Tur FC, Sever M, Kaya A (2015) Sensitivity and specificity of bedside ultrasonography in the diagnosis of fractures of the fifth metacarpal. Emerg Med J 32(3):221-225

217. Aksay E, Kilic TY, Yesılaras M, Tur FC, Sever M, Kalenderer O (2016) Accuracy of bedside ultrasonography for the diagnosis of finger fractures. Am J Emerg Med 34(5):809-812

218. Gungor F, Akyol KC, Eken C, Kesapli M, Beydilli I, Akcimen M (2016) The value of point-of-care ultrasound for detecting nail bed injury in ED. Am J Emerg Med 34(9):1850-1854

219. Kocaoğlu S, Özhasenekler A, Içme F, Pamukçu Günaydın G, Şener A, Gökhan \$̧ (2016) The role of ultrasonography in the diagnosis of metacarpal fractures. Am J Emerg Med 34(9):1868-1871

220. Kozaci N, Ay MO, Avci M, Turhan S, Donertas E, Celik A, Ararat E, Akgun E (2017) The comparison of point-of-care ultrasonography and radiography in the diagnosis of tibia and fibula fractures. Injury 48(7):1628-1635

221. Atilla OD, Yesilaras M, Kilic TY, Tur FC, Reisoglu A, Sever M, Aksay E (2014) The accuracy of bedside ultrasonography as a diagnostic tool for fractures in the ankle and foot. Acad Emerg Med 21(9):1058-1061

222. Tollefson B, Nichols J, Fromang S, Summers RL (2016) Validation of the Sonographic Ottawa Foot and Ankle Rules (SOFAR) study in a large urban trauma center. J Miss State Med Assoc 57(2):35-38

223. Ozturk P, Aksay E, Oray NC, Bayram B, Basci O, Tokgoz D (2018) The accuracy of emergency physician performed ultrasonography as a diagnostic tool for lateral malleolar fracture. Am J Emerg Med 36(3):362-365

224. Yesilaras M, Aksay E, Atilla OD, Sever M, Kalenderer O (2014) The accuracy of bedside ultrasonography as a diagnostic tool for the fifth metatarsal fractures. Am J Emerg Med 32(2):171-174

225. Kozaci N, Ay MO, Avci M, Beydilli I, Turhan S, Donertas E, Ararat E (2017) The comparison of radiography and point-of-care ultrasonography in the diagnosis and management of metatarsal fractures. Injury 48(2):542-547

226. Fagan TJ (1975) Letter: Nomogram for Bayes theorem. N Engl J Med 293(5):257

\section{Publisher's Note}

Springer Nature remains neutral with regard to jurisdictional claims in published maps and institutional affiliations.

\section{Submit your manuscript to a SpringerOpen ${ }^{\circ}$ journal and benefit from:}

- Convenient online submission

- Rigorous peer review

- Open access: articles freely available online

- High visibility within the field

- Retaining the copyright to your article

Submit your next manuscript at springeropen.com 